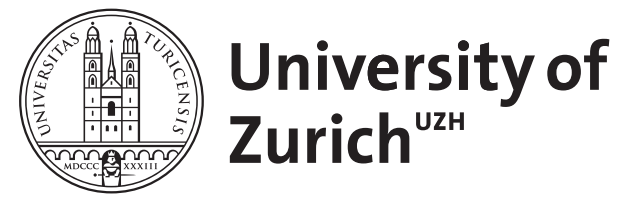

Zurich Open Repository and Archive

University of Zurich

University Library

Strickhofstrasse 39

CH-8057 Zurich

www.zora.uzh.ch

Year: 1992

Freiräume literarischer Theoriebildung - Dimensionen und Grenzen programmatischer Aussagen in der deutschen Literatur des 12. Jahrhunderts

\author{
Kiening, Christian
}

Posted at the Zurich Open Repository and Archive, University of Zurich

ZORA URL: https://doi.org/10.5167/uzh-113631

Journal Article

Published Version

Originally published at:

Kiening, Christian (1992). Freiräume literarischer Theoriebildung - Dimensionen und Grenzen programmatischer Aussagen in der deutschen Literatur des 12. Jahrhunderts. Deutsche Vierteljahrsschrift für Literaturwissenschaft und Geistesgeschichte, 66:405-449. 


\title{
Freiräume literarischer Theoriebildung Dimensionen und Grenzen programmatischer Aussagen in der deutschen Literatur des 12. Jahrhunderts
}

\author{
Von Christian Kiening (München)
}

\section{ABSTRACT}

Eine Zusammenschau literaturtheoretischer Äußerungen vor allem in Prologen und Epilogen frühmittelhochdeutscher Texte soll den vielschichtigen und uneinheitlichen Prozeß literarischer Entwicklung und Theoriebildung beleuchten und dabei methodische Fragen, Kontinuitäts- und Innovationsverständnis betreffend, neu aufwerfen.

This essay is a survey of selected passages concerning literary theory in early middle high German texts. I attempt to demonstrate the multifarious and indeed far from homogeneous process of literary evolution, and to raise again the methodological issues of continuity and innovation.

\section{I.}

"Theorie ist etwas, was man nicht sieht. Zwar besteht theoretisches Verhalten aus Handlungen, die unter intentionalen Regeln stehen und zu Komplexen von Aussagen in regulierten Zusammenhängen führen, aber diese Handlungen sind nur mit ihrer Außenseite als 'Verrichtungen' sichtbar. Einem in ihre Intentionalität nicht Eingeweihten, sie vielleicht nicht einmal ihrem Typus nach als 'Theorie' Vermutenden, müssen sie rätselhaft bleiben, können sie anstößig oder sogar lachhaft erscheinen." Paradigmatisch für dieses in der Sicht von "Welt- und Zeitgenossen' exotische oder höchstens halbwegs vertraute Theoretische ist die seit Platon überlieferte Anekdote vom Brunnensturz des in die Betrachtung der Gestirne 'versunkenen' Protophilosophen Thales und dem Gelächter seiner einzigen Zuschauerin, einer thrakischen Magd. Theoretisches Verhalten enthüllt sich in den Spiegelungen späterer Positionen als keineswegs selbstverständlicher Akt philosophischer oder wissenschaftlicher Betrachtung, immer wieder auf Selbstreflexion angewiesen, weder durch Vermehrung und Verfeinerung des Wissens noch durch Aktualisierung ursprünglicher begrifflicher Sinnschichten ${ }^{2}$

\footnotetext{
${ }^{1}$ Hans Blumenberg, Das Lachen der Thrakerin: Eine Urgeschichte der Theorie, stw, 652 (1987), S. 9.

2 S. Wolfgang Schadewaldt, Die Anfänge der Philosophie bei den Griechen: Die Vorsokratiker und ibre Voraussetzungen, Tübinger Vorlesungen Bd. I, stw, 218, 5. Aufl. (1988), S. $181 \mathrm{ff}$.; Hans-Georg Gadamer, Lob der Theorie: Reden und Aufsätze, Bibliothek Suhrkamp, 828 (1983), S. 26-50.
} 
zu sichern. Die Adaptationen und Transformationen der Anekdote, die Hans Blumenberg vorführt, zeigen nicht nur wechselnde Einstellungen der Philosophen zu ihrem eigenen Tun, sondern auch Spannungen verschiedener Verstehenshorizonte und Theoriebewußtheit, damit das problematische Verhältnis der Theorie zu ihren eigenen Voraussetzungen wie lebensweltlichen Verankerungen.

Die Frage nach einer 'Urgeschichte der Theorie,' die ich im folgenden anhand der deutschen Literatur des 12. Jahrhunderts aufgreifen will, erweist sich solchermaßen als eine, deren historischer Charakter nicht gänzlich abhebbar ist von der systematischen Position des Frageansatzes. So bedingt die Suche nach frühen Formen literarisch-volkssprachlicher Theoriebildung im Mittelalter nicht nur eine Freilegung rudimentärer Schichten, sie beruht vielmehr auch auf einem veränderten Interesse und einer gewandelten Sensibilität angesichts bekannter Erscheinungen. Versteht man literarische Theoriebildung nicht notwendig als systematische Diskursform im Gefolge von Aristoteles und Horaz ${ }^{3}$ - die im Deutschen, verspätet gegenüber der Romania, ${ }^{4}$ erst mit den Meistersingertabulaturen und Prosodien des 16. Jahrhunderts, dann vor allem mit Opitz einsetzt $^{5}$-, sondern ebenso im Sinne unsystematischer poetologischer Aussageformen im Medium der Dichtung selbst (wie sie bereits bei Homer und Aristophanes begegnen), so bietet sich jenes andere Bild historischer Entwicklung, das Walter Haug für die mittelalterliche deutsche Literatur erstmals konsistent entworfen hat, ${ }^{6}$ jenes Bild einer Theorie, die weder um ihren Namen weiß noch ihn, im modernen Sinne, verdient, deren Ansätze aber wichtige Züge volkssprachlicher Literarisierung erhellen. Diese erst nach adäquater Terminologie suchende Form von theoria, die vom jeweiligen Text ausgeht und nicht auf

${ }^{3}$ Úberblick mit Literatur bei H.-D. Blume, "Poetik (1. Antike)," Historisches Wörterbuch der Philosophie, Bd. VII (1989), 1011-1017. Zum Weiterleben s. Paul Klopsch, Einführung in die Dichtungslehren des lateinischen Mittelalters (1980), S. $40 \mathrm{ff} . ;$ und Texte (in Ubersetzung) zur lateinischen Literaturtheorie jetzt in Medieval Literary Theory and Criticism c. $1100-$ c. 1300: The Commentary Tradition, edd. A. J. Minnis and A.B. Scott (1988).

${ }^{4}$ Im Italienischen mit Dichtungstheorien und Poetiken spätestens im Quattrocento (Bembo, Della Fonte), im Französischen systematisch mit dem 'Brigade'-Kreis (1547) und Sebillet; Einführungen und Texte bei August Buck, Klaus Heitmann, Walter Mettmann, Dichtungslehren der Romania aus der Zeit der Renaissance und des Barock, Dokumente zur europäischen Poetik, 3 (1972). Zur Herausbildung der nationalen Schriftsprachen und ihrer theoretischen Fundierung s. Karl-Otto Apel, Die Idee der Sprache in der Tradition des Humanismus von Dante bis Vico, 3. Aufl. (1980).

5 Zu Martin Opitz (Buch von der Deutschen Poeterey [1624]), seinen Voraussetzungen und Nachfolgern immer noch wichtig Karl Borinski, Die Poetik der Renaissance und die Anfänge der litterarischen Kritik in Deutschland, Nachdr. (1967); neuere Literatur bei H. Wiegmann, "Poetik (II. Vom Mittelalter bis zur Aufklärung)," Hist. Wörterb. (Anm. 3), 1017-1021.

6 Walter Haug, Literaturtheorie im deutschen Mittelalter: Von den Anfängen bis zum Ende des 13. Jahrbunderts (1985). 
das Allgemeine von Literatur zielt, die sich logisch und terminologisch meist unzureichend vor allem (aber nicht nur) in Prologen und Epilogen mittelalterlicher volkssprachiger Autoren kundtut, 7 die mehr den Ausdruckswillen als die Präzision eines theoretischen Programmes offenbart, stellt auch die methodologische Reflexion vor neue Probleme. Gefordert ist ein rekonstruierendes Verfahren, herausgefordert zugleich das hermeneutische Bedenken angesichts eines Entwurfs, der das Unsystematische erschließen soll, ohne es durch Integration in lateinische Ästhetik oder Rhetorik bzw. durch textübergreifende Konstruktion inadäquat zu systematisieren. ${ }^{8}$ Die Untersuchung bedarf eines sowohl methodisch wie analytisch verfeinerten Instrumentariums, um ein komplexes Phänomen der Theoriebildung im Kontext seiner kulturellen Situation angemessen zu erfassen. Und sie bedarf der diachronen wie synchronen Absicherung gegenüber den Determinanten und Brüchen der Tradition wie gegenüber der immanenten Logik und narrativen Realisation des Werkes selbst. Angesprochen ist damit auch das für das europäische Mittelalter virulente Problem, nicht den oft konventionellen Charakter des unsystematisch, verstreut 'Theoretischen' zu verfehlen und dieses doch aus dem Bann eines rhetorischen Modells, einer stringentsynchronen Topik zu lösen, die Entwicklung und Innovation primär als Verwirklichung scheinbar invarianter Typen und Kategorien erscheinen läßt. ${ }^{9}$

Walter Haug hat hier angesetzt mit der Einsicht, daß "Konventionalität und Reflexion ... wie Wasser und Feuer zischend aufeinandertreffen oder bloß einen warmen Aufguß des Überkommenen abgeben" können, ${ }^{10}$ und hat für eine Untersuchung volkssprachiger literarischer Theoriebildung interpretatorische Maßstäbe vorgegeben und zugleich Impulse vermittelt zu Weiterführung und

\footnotetext{
7 Zur Notwendigkeit, nicht nur Prologe und Epiloge, sondern die über das Werk verstreuten 'Erzählerbemerkungen' zu erfassen, schon Bernd Naumann, "Vorstudien zu einer Darstellung des Prologes in der deutschen Dichtung des 12. und 13. Jahrhunderts," Formen mittelalterlicher Literatur: Siegfried Beyschlag zu seinem 65. Geburtstag, hrsg. Otmar Werner, B. Naumann, Göppinger Arbeiten zur Germanistik, 25 (1970), S. 25-37, hier S. 35, Anm. 6; ich habe versucht, das Problem am Beispiel des Willehalm ausführlich darzulegen: Reflexion - Narration: Wege zum 'Willehalm' Wolframs von Eschenbach, Hermaea, 63 (1991).

${ }^{8}$ Beispiel für den ersten Fall Hennig Brinkmann, $\mathrm{Zu}$ Wesen und Form mittelalterlicher Dichtung, Nachdr. (1979), wo die "theoretischen Äußerungen der Dichter" (S. 10-29) zwischen scholastischer Kunsttheorie und lateinisch-poetischer Tradition ihren Platz finden; für den zweiten Fall Bruno Boesch, Die Kunstanschauung in der mittelhochdeutschen Dichtung von der Blütezeit bis zum Meistergesang (1936).

${ }^{9}$ Literatur zur Auseinandersetzung mit Ernst Robert Curtius, Europäische Literatur und lateinisches Mittelalter (1948) bei Haug (Anm. 6), S. 11 f.; s. a. Peter Dronke, Poetic Individuality in the Middle Ages: New Departures in Poetry 1050-1150 (1970), bes. S. 1-22, und Peter Godman im Nachwort zur engl. Ubersetzung von ELLMA (1990).

${ }^{10}$ Haug (Anm. 6), S. 3.
} 
Widerspruch. ${ }^{11}$ Daß innerhalb einer Zusammenschau literaturtheoretischer Äußerungen im narrativen Kontext mittelalterlicher deutscher Epik jene Entwürfe des 'klassischen' höfischen Romans einen zentralen Platz einnehmen, die in der Übernahme der matière de Bretagne, der Adaptation von oder Antwort auf Chrétien de Troyes den fiktionalen Roman und mit ihm ein tiefsinnig-erzählimmanentes 'Korrelationskonzept' im deutschsprachigen Raum einführten und weiterentwickelten, liegt auf der Hand. ${ }^{12}$ Die neue literarische Reihe, ${ }^{13}$ die mit Hartmann, Wolfram und Gottfried einsetzt, erprobt nicht nur prozessuale, strukturell-symbolisch entfaltete Sinnkonzeptionen neuer Radikalität, öffnet sich vielmehr auch einer Reflexion der Bedingungen des Erzählens, der Möglichkeiten und Ansprüche von Literatur im allgemeinen, die in ihrer narrativen Immanenz auf eine epochale Wende, in ihrer Differenziertheit weit in die $\mathrm{Zu}$ kunft weist.

Diese systematische Positionsbestimmung des höfischen Romans und seiner theoretischen Konstitution führt zugleich auf die Frage nach der Gültigkeit und Spannweite historisch-analytischer Kategorien, damit auf die Konfrontation mit Ansätzen und Modellen moderner wissenschaftlicher Theoriebildung wieder zurück. Zu fragen ist, inwieweit ein epochales Modell einem weitgehend typologisch denkenden Zeitalter angemessen sein kann, ${ }^{14}$ inwieweit der Blick auf einschneidende Innovationen, auf eindeutige serielle Positionen Entwicklungsvorgänge und zaghafte Ansätze ausreichend konturieren kann; ${ }^{15}$ wenn man

${ }^{11}$ Auseinandersetzung mit verschiedenen Interpretationsakzenten bei Joachim Heinzle, "Die Entdeckung der Fiktionalität: Zu Walter Haugs 'Literaturtheorie im deutschen Mittelalter,'” PBB, 112 (1990), 55-80; zum implizierten Verständnis von mittelalterlicher Fiktionalität und Autonomie besonders Christoph Huber, AfdA, 99 (1988), 60-68.

12 Weitergeführt von Walter Haug u.a. in den Beiträgen "Literatur und Leben im Mittelalter: Eine neue Theorie zur Entstehung und Entwicklung des höfischen Romans," $D U, 41$, No. 1 (1989), 12-26; "Wandlungen des Fiktionalitätsbewußtseins vom hohen zum späten Mittelalter," Entzauberung der Welt: Deutsche Literatur 1200-1500, hrsg. James F. Poag und Thomas C. Fox (1989), S. 1-17.

${ }^{13}$ Zum Begriff der literarischen Reihe: Jurij Tynjanov, "Uber die literarische Evolution," Russischer Formalismus: Texte zur allgemeinen Literaturtheorie und zur Theorie der Prosa, hrsg. Jurij Striedter, 3. Aufl (1981), S. 433-461; generell: George Kubler, The Shape of Time: Remarks on the History of Things (1962); dt. mit einer Einleitung von Gottfried Boehm: Die Form der Zeit: Anmerkungen zur Geschichte der Dinge (1982).

${ }_{14}$ Walter Haug, "Die Zwerge auf den Schultern der Riesen: Epochales und typologisches Geschichtsdenken und das Problem der Interferenzen," Epochenschwelle und Epochenbewußtsein, hrsg. Reinhart Herzog und Reinhart Koselleck, Poetik und Hermeneutik, 12 (1987), S. 167-194; wieder in: ders., Strukturen als Schlüssel zur Welt: Kleine Schriften zur Erzählliteratur des Mittelalters (1989), S. 86-109.

${ }_{15} \mathrm{Zu}$ rekurrieren ist im folgenden vor allem auf Haug (Anm. 6), S. 46-74: "Allegorese und Entscheidung: Literaturtheoretische Positionen in frühmittelhochdeutscher Zeit." Die Differenzierung von Haug, Literatur und Leben (Anm. 12) durch Einbeziehung des Ruodlieb-Romans betrifft primär den fiktionalen Status des höfischen Romans, nicht das Problem vorausliegender Reihen. 
historische Abläufe begreift "als strukturierte Bündelungen von Konstanten mit einem Spielraum von Variablen,"16 ist dennoch je von neuem zu klären, wo Innovation, wo eine Veränderung auch von Konstanten stattfindet. Nicht nur serielle Übergänge, bereits die Konstitutionen signifikanter Reihen selbst entziehen sich verschiedentlich der Evidenz.

Den programmatischen Außerungen in der erzählenden und didaktischen deutschen Literatur des 12. Jahrhunderts fehlt die Konsistenz, aber auch der Bezug auf zentrale Texte, deren initiale serielle Position offensichtlich wäre. Zwar lassen sich die meist geistlichen poetischen Versuche immerhin insofern zusammenschließen, als sie überwiegend Antwort zu geben versuchen auf die gemeinsame Grundfrage nach der Möglichkeit volkssprachlicher Vermittlung von Heilswissen an ein kaum lateinisch gebildetes Publikum, eine literarische Reihe aber ist aufgrund stofflich-thematischer Vielfalt, aufgrund von Ungleichzeitigkeiten und Unabhängigkeiten der Denkmäler kaum zu bilden. Daraus darf allerdings nicht die Gefahr erwachsen, die frühmittelhochdeutsche Literatur und ihre theoretischen Ansätze von neuem im Zeichen des Vorläufigen und auf das Telos des höfischen Romans bezogen zu interpretieren und damit die historische wie methodische Spannung zwischen den Vorgaben lateinisch-geistlicher Tradition und den je neuen volkssprachlich-literarischen Experimenten zu reduzieren. Vielmehr gehören bereits die tastenden Versuche zu dem Prozeß, der über reflexionslose heilsgeschichtliche Basisunterweisung hinausführt, zu den Freiräumen, die sich die neu einsetzende deutschsprachige Literatur des ausgehenden 11. und des 12. Jahrhunderts, was Stoffe und Themen, Stil und Deskriptionstechnik angeht, erobert. ${ }^{17} \mathrm{Zu}$ beobachten ist eine allmähliche Emanzipierung aus lateinisch-klerikaler Tradition, ist die anwachsende Souveränität der volkssprachlichen Entwürfe im Übergang von Bibelparaphrase und -kommentar zur Erzählung bibelfernerer, legendarischer, schließlich weltlich-historischer Stoffe, im Gewinn von Detailgenauigkeit, Intensität und lebensweltlichem Bezug der Schilderung, in der Verfeinerung der Reimtechnik und metrischen Formung. Dieser Prozeß der Literarisierung, der auch die Transformation genuin mündlichen Erzählguts in die Schriftlichkeit erfaßt, konstituiert ungeachtet ungleichzeitiger Elemente und ungleicher literarischer Talente eine formale und thematische Vielfalt, die sich etwa von der Mitte des 12. Jahrhunderts an auch

\footnotetext{
${ }^{16}$ Haug (Anm. 14), S. 92.

${ }^{17}$ Grundsätzlich hinzuweisen ist auf die fruchtbaren Darlegungen bei Gisela VollmannProfe, Von den Anfängen zum bohen Mittelalter: Wiederbeginn volkssprachiger Schriftlichkeit im hohen Mittelalter, Geschichte der deutschen Literatur von den Anfängen bis zum Beginn der Neuzeit, I, 2 (1986) und Dieter Kartschoke, Geschichte der deutschen Literatur im frühen Mittelalter, dtv, 4551 (1990). Die Texte werden im folgenden in der Mehrzahl zitiert nach Die religiösen Dichtungen des 11. und 12. Jahrhunderts, hrsg.
} 
in den Reflexionsansätzen auszuprägen beginnt. Konstanten geistlicher Tradition wirken dabei - aus der Notwendigkeit heraus, die richtige Vermittlung und Aufnahme der Heilswahrheit zu sichern - fort, werden aber zunehmend individuell geformt. Stehen die meisten programmatischen Passagen auch weiterhin unter dem Zeichen topischer, traditioneller oder predigthafter Wendungen, unter dem Zeichen göttlicher Präsenz, ${ }^{18}$ so scheinen sie im Kontext doch von einer veränderten, selbst bereits literarisch beeinflußten 'gesellschaftlichen Einbildungskraft' infiziert. ${ }^{19}$ Die Aussageformen sind überwiegend bekannt: beklagt werden Neider und Kritiker, abgewiesen schlechte Zuhörerschaft und heilsgeschichtlich nicht werthaftes Erzählen; über Schöpfungspreis, Bitte um Inspiration und Erflehen rechter Sprachfähigkeit konstituiert sich der Bezug zwischen dem meist anonymen demütigen Subjekt und Gott; gespeist aus dem göttlichen Initiations- und Gnadenakt weist die rede auch wieder auf das absolute göttliche Sein zurück - einmal im Lobe verharrend, ein andermal mehr die Differenz zu allem Irdischen und damit dessen Nichtigkeit betonend. ${ }^{20}$ Diese Konstanten jedoch sind weder uniform noch trivial, ${ }^{21}$ ihr Auftreten gehört in den Kontext der grundlegenden Dialektik christlicher Sprache (zwischen apophatischer und kataphatischer Orientierung), der zugleich volkssprachlich neu entworfen wird. Die Texte kreisen damit um das Phänomen christlicher Aussage,

Friedrich Maurer, 3 Bde. (1964-70); Kleinere deutsche Gedichte des 11. und 12. Jahrbunderts, nach der Auswahl von Albert Waag hrsg. von Werner Schröder, ATB, 71/72, 2 Bde. (1972) [unter gleichem Titel ebenfalls nach der Waagschen Ausgabe hrsg. Hans Joachim Gernentz, 5. Aufl. (1987)].

${ }_{18}$ Allgemeine Literatur vor allem in den beiden ersten Kapiteln bei Haug (Anm. 6); konkret etwa Bernd Naumann, "Ein- und Ausgänge frühmittelhochdeutscher Gedichte und die Predigt des 12. Jahrhunderts," Studien zur frühmittelhochdeutschen Literatur: Cambridger Colloquium 1971, hrsg. L.P. Johnson, H.-H. Steinhoff und R.A. Wisbey (1974), S. 37-57; C. Stephen Jaeger, "Der Schöpfer der Welt und das Schöpfungswerk als Prologmotiv in der mittelhochdeutschen Dichtung," ZfdA, 107 (1978), 1-18.

19 Lothar Bornscheuer, Topik: Zur Struktur der gesellschaftlichen Einbildungskraft (1976). Zur lateinischen Prologtradition und -rhetorik James A. Schultz, "Classical Rhetoric, Medieval Poetics, and the Medieval Vernacular Prologue," Speculum, 59 (1984), 1-15 mit der summarischen Feststellung: "It seems that the rapid growth of vernacular literature in France and Germany led to the development of prologue traditions quite independent of the classical rhetorical tradition taught in the schools and of the medieval prescriptive poetics that grew out of them" (15).

${ }^{20}$ Beispiele Haug (Anm. 6), S. 46ff.; umfassende Belegsammlung bei Julius Schwietering, Die Demutsformel mittelhochdeutscher Dichter (1921); wieder in: ders., Philologische Schriften, hrsg. Friedrich Ohly und Max Wehrli (1969), S. 140-215.

${ }^{21}$ Die "Uniformität der frühmittelhochdeutschen Dichtung" ist Basis für die umfassende, aber in zeit- und geistesgeschichtlichen Kategorien problematische Darstellung von Susanne Gerhaher, Der Prolog des 'Annoliedes' als Typus in der frühmittelhochdeutschen Literatur (1965), hier S. 116ff. (Kap. II, S. 23-116: "Das Programm der frühmittelhochdeutschen Prologe"). 
die Linearität und elementare Geschichtlichkeit der diachronen Reihe, die Entfaltung des Heilswerks in der Geschichte, je neu aufzubrechen in der unmittelbaren, synchronen Relation zwischen Mensch und Gott, die die Sprache selbst sich durch alle Negativität hindurch zu formulieren müht. Diese Position christlicher Literatur im Spannungsfeld von Geschichte und Augenblick, von Paradigmatik und Syntagmatik angesichts der Möglichkeiten religiöser Sprache ${ }^{22}$ läßt sich wohl nicht völlig mit der (eher fluktuierenden) Differenz zwischen Welt als Theophanie oder unerfülltem Signum, zwischen "Dichtung als Einstimmung ins Schöpfungswerk" oder Darstellung eines zeichenhaft-unerfüllten Kosmos ${ }^{23}$ verrechnen. Der Balanceakt zwischen heilsgeschichtlichem Basisgehalt und literarischer Neuformung ist für jeden Text, jede Passage neu zu vollziehen, um die nur reflexhaft greifbare Eigendynamik frühmittelhochdeutscher literarischer Ansätze nicht im übermächtigen Hintergrund ontologisch-ästhetischer Voraussetzungen aufgehen zu lassen. Denn auch die Freiräume gegenüber der normativen Linearität und Zielbestimmtheit christlicher Metaphysik formieren sich nicht erst durch Systeme neuer Gattungen und neuer Subjektivitäten, ${ }^{24}$ sondern bereits in immanenten Ausweitungen, auch wo diese nicht stringent die Sprengung eines Systems bewirken.

$\mathrm{Da}$ das Instrumentarium noch kaum hinreicht, exakt den verpflichtenden Raum der Tradition einerseits, dessen Erweiterung oder Durchbrechung andererseits auszumessen, ist allerdings nur zu deutlich. In dem vieldimensionalen Koordinatensystem aus literarischen, sozialen, mentalen Determinanten sind die Positionen der frühmittelhochdeutschen Entwürfe nur approximativ zu bestimmen: zu fragmentarisch ist weiterhin das Wissen um die volkssprachlichen Texte und Kontexte des 12. Jahrhunderts, zu unkonkret der Bezug der Denkmäler zur sozialen und politischen Realität, zu unentwickelt noch die historische Anthropologie und Psychologie, die die Relation einer sich etablierenden Literatur zur mentalen Entwicklung einer ständisch und geographisch differenzierten Gesellschaft zu konkretisieren hätte. Die Raumgewinne literarischer Reflexion drohen sich damit, wo sie im Detail fixiert werden sollen, nur zu leicht zu verflüchtigen. Textüberschreitende Rahmenbedingungen bleiben zunächst meist unscharf: die Texte entstehen in der Regel ohne Beziehung aufeinander; ihre absolute und

\footnotetext{
22 Eher systematische als historische Ansätze in dem Sammelband Probleme der religiösen Sprache, hrsg. Manfred Kaempfert, Wege der Forschung, 442 (1983); hermeneutisch: Paul Ricœur, Eberhard Jüngel, Metapher: Zur Hermeneutik religiöser Sprache. Mit einer Einfübrung von Pierre Gisel (1974).

${ }^{23}$ Haug (Anm. 6), S. 20f. u.ö. (hier S. 47).

${ }^{24}$ Haug (Anm. 14), bes. S. 107-109. Ebenfalls primär auf den höfischen Roman bezogen: Peter Czerwinski, Der Glanz der Abstraktion: Frübe Formen von Reflexivität im Mittelalter (1989).
} 
relative Chronologie ist oft genug zweifelhaft, ${ }^{25}$ literarische Zentren, die einen Prozeß der Intertextualität in Gang brächten, werden, von Regensburg abgesehen, kaum greifbar; Verfasserprofile und Publikumsgemeinschaften, Bildungsvoraussetzungen und Verständnisbedingungen lassen sich häufig nur aus den Implikationen der Texte rekonstruieren - in unterschiedlicher Plausibilität. ${ }^{26} \mathrm{Die}$ Analyse hat sich also den Texten selbst anzuvertrauen, hat Terminologie, Metaphorik und Struktur signifikanter Stellen, hat das jeweilige Verhältnis von Implizitem und Explizitem zu erfassen und schließlich den Übergang zu größerer programmatischer Ausdrücklichkeit und zunehmend konstitutiver Intertextualität (ab etwa 1150/70) anzudeuten. Der folgende Durchgang versucht (nach Möglichkeit chronologisch), die Reflexionselemente einerseits der geistlichen Literatur zwischen Ezzolied und Pilatus (II), andererseits der seit 1150 greifbaren 'weltlichen' Literatur (III) darzustellen, damit "Leitfossilien einer archaischen Schicht des Prozesses der theoretischen Neugierde" ${ }^{27}$ zu präparieren - in einem Verfahren textueller Archäologie, das die verstreuten Reflexionsansätze

${ }^{25}$ Deshalb werden im folgenden Datierungen der handschriftlichen Zeugen mitangegeben, die sich beziehen auf die den aktuellen Stand repräsentierende Liste bei Ernst Hellgardt, "Die deutschsprachigen Handschriften im 11. und 12. Jahrhundert: Bestand und Charakteristik im chronologischen Aufriß," Deutsche Handschriften 1100-1400: Oxforder Kolloquium 1985, hrsg. Volker Honemann und Nigel F. Palmer (1988), S. 35-81.

${ }^{26}$ S. Bernd Naumann, Dichter und Publikum in deutscher und lateinischer Bibelepik des frühen 12. Jahrhunderts, Erlanger Beiträge zur Sprach- und Kunstwissenschaft, 30 (1968); außerdem Vollmann-Profe (Anm. 17), pass. und sehr konzise Kartschoke (Anm. 17), S. 217-220. Die Autoren, die sich manchmal phaffen, priester oder ewart nennen, als arm oder armen chnecht bezeichnen (Übersicht bei Naumann [Anm. 18], S. 40f.), dürften aus Kreisen von Klerikern wie Weltpriestern, von Mönchen, Stiftsherren, Scholastici gleichermaßen kommen, das implizierte un- bzw. mäßig gelehrte, höchstens ansatzweise lateinisch gebildete Publikum sich aus Kreisen von Laien und weniger theologisch geschulten Geistlichen, z.B. aus der heterogen zusammengesetzten familia an Bischofssitzen, kleineren Adelshöfen oder 'mittelmäßigen' Klöstern rekrutieren (Achim Masser, Bibel- und Legendenepik des deutschen Mittelalters, Grundlagen der Germanistik, 19 [1976], S. 43f.). Die spezifische Anrede an die herron im Ezzolied (s.u.) bleibt ebenso eher ungewöhnlich wie die Möglichkeit, aus Einsprengseln sozialer Realität im Gedicht Vom Rechte (Waag/Schröder [Anm. 17] II, 112-131, v. 163-184) vielleicht eine dörflich-ländliche oder zumindest mit den Problemen von Landnahme und Ertragsverteilung vertraute Bezugsgruppe zu erkennen (vgl. Stephan Speicher, 'Vom Rechte': Ein Kommentar im Rabmen der zeitgenössischen Literaturtradition, Göppinger Arbeiten zur Germanistik, 443 [1986], S. $48 \mathrm{ff}$.) oder in den gegen Wucherzins und Falschaussage polemisierenden Passagen im Werk des Wilden Mannes vielleicht eine stadtbürgerliche Schicht aufs Korn genommen zu sehen (s. Vollmann-Profe [Anm. 17], S. 187). Die im Prolog des St. Trudperter Hohenliedes (hrsg. Hermann Menhardt, Rheinische Beiträge, 22 [1934]) angesprochenen geistlichen mennisken (Z. 3) erweisen sich im weiteren Verlauf des Textes v. a. als Mitglieder von Frauenkonventen; vgl. Anm. 82.

${ }^{27}$ Hans Blumenberg, "Ausblick auf eine Theorie der Unbegrifflichkeit," Schiffbruch mit Zuschauer: Paradigma einer Daseinsmetapher, stw, 289, 3. Aufl. (1988), S. 77-93, hier S. 77. 
zu sammeln, aber auch deren individuelle Aussageleistung durch die Überlagerungen formelhafter Elemente und konventioneller rhetorischer Strategien hindurch zu eruieren unternimmt. ${ }^{28}$

II.

Reflexe literarischer Situierung bieten zunächst zwei Texte, deren Entstehungsinteresse ungewöhnlich gut greifbar wird: Ezzolied und Annolied.

Am Ezzolied, ${ }^{29}$ entstanden in der Urfassung zwischen 1057 und 1065, lassen sich Aspekte literarischer Bewußtheit ablesen, unabhängig davon, was man ansonsten vom Ursprünglichen in den beiden überlieferten Versionen zu erkennen glaubt. ${ }^{30}$ Aus den in der Eingangsstrophe der älteren Fassung (Straßburger Handschrift, bald nach 1130) angesprochenen herron ${ }^{31}$ hat der Bearbeiter der jüngeren (Vorauer Sammelhandschrift, Ende 12. Jhdt.) ${ }^{32}$ eben alle gemacht, die spezifische Anrede an ein adliges Publikum ins Universale der christlichen Gemeinschaft, einer nicht schichtenspezifisch eingegrenzten Zuhörerschaft ausgeweitet. Vorgeschaltet hat er wohl zugleich eine Strophe, die Entstehung und Wirkung des Liedes genau angibt:

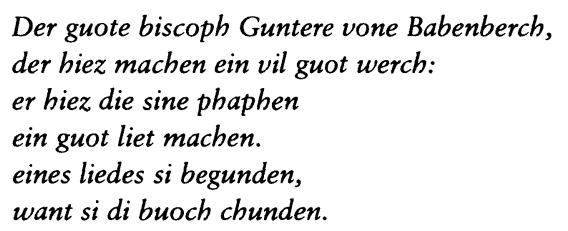

${ }^{28}$ Zur Methode generell: Michel Foucault, L'archéologie du savoir (1969); dt.: Archäologie des Wissens, stw, 356, 4. Aufl., (1990); Ulrich Johannes Schneider, Die Vergangenheit des Geistes: Eine Archäologie der Philosophiegeschichte (1990). Außerdem die von Aleida und Jan Assmann herausgegebenen Beiträge zur Archäologie der literarischen Kommunikation, 3 Bde. (1983/87/91) [vgl. Anm. 181].

$29 \mathrm{Waag} /$ Schröder [Anm. 17] I, 1-26.

${ }^{30} \mathrm{Zu}$ den älteren Versuchen Hartmut Freytag ("Ezzos Gesang: Text und Funktion," Geistliche Denkformen in der Literatur des Mittelalters, hrsg. Klaus Grubmüller u.a., Münstersche Mittelalter-Schriften, 51 [1984], S. 154-170), der dafür votiert, die Suche nach dem $U r$-Ezzo aufzugeben und sich auf die überlieferten Fassungen zu beschränken. Im Hinblick auf eine Entstehung des Textes in Zusammenhang mit dem Palästinazug, "der die Pilger am Ostermorgen des Jahres 1065 vor das Heilige Grab in Jerusalem führen sollte," scheint ihm die Vorauer Fassung im wesentlichen der ursprünglichen zu entsprechen (S. 169f.).

${ }^{31}$ Als Ansprechpartner ebenfalls genannt bei Ava, Leben Jesu (Maurer [Anm. 17] II, 398-491) 28, 1 (V. 297); Altdeutsche Exodus, hrsg. Edgar Papp, Altdeutsche Texte in kritischen Ausgaben, 2 (1969), V. 2907; eventuell schon in der Wiener Genesis (hrsg. Kathryn Smits, Philologische Studien und Quellen, 59 [1972]), V. 1f., wo der Reimbefund eine redaktionelle Änderung denkbar macht: $\mathrm{Nu}$ fer nemet, mine liebe, / ich wil iu aine rede fore tuon (s. Kartschoke [Anm. 17], S. 289).

${ }^{32}$ Hellgardt (Anm. 25), Nr. 103 (S) und 187 (V). 


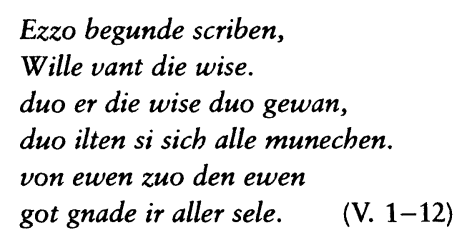

Der Scholasticus Ezzo, von dem die Vita Altmanni um 1130 spricht und den vielleicht auch Urkunden bezeugen, ${ }^{33}$ erscheint in der Prologstrophe als Erfüllungsgehilfe der von Bischof Gunther von Bamberg in Auftrag gegebenen dichterischen Produktion, der weiter nicht bekannte Wille als Urheber der Melodie alles zusammen also eine gemeinschaftliche gelehrte Arbeit mit durchschlagendem gemeinschaftlichen Erfolg: ${ }^{34}$ der Hinweis auf die Wirkung des Liedes (duo ilten si sich alle munechen), im allgemeinsten Sinne verstanden als Unternehmen, "sich auf eine mönchische Lebensweise zu verpflichten," ${ }^{35}$ begründet die Verbindlichkeit und Vortrefflichkeit des Textes und läßt mit der so gesetzten Mittelbarkeit Literatur selbst als geformtes Medium des Göttlichen hervortreten. Der Text steht zwar - vermittelt durch das Ich des Sprechers in der Anrede an das göttliche Du (S 17/V 55) - wie die meisten Texte der Folgezeit direkt zu Gott, konstituiert sich jedoch mit seiner spezifischen Vorrede, die dem Weiteren Zitatcharakter verleiht, als Wiederholungsereignis, als Aspekt der Geschichtlichkeit von Literatur, überschreitet damit eine 'Bewußtseinsschwelle' der ansonsten "historisch nicht reflektierten Laienkultur." Während die mutmaßlich ursprüngliche Fassung des von Gunther, dem heldensageninteressierten Bischof, ${ }^{37}$ initiierten geistlich-gelehrten Liedes diese Geschichtlichkeit vielleicht mittelbar in der Anknüpfung an heimisch-germanische Tradition zu schaffen

33 Vita Altmanni, hrsg. Wilhelm Wattenbach, MGH SS, XII, S. 230, 11f. (Kap. 3) anläßlich des großen Palästinazuges, 1064/65: Ezzo scolasticus ... cantilenam de miraculis Christi patria lingua nobiliter composuit; zum Namen Ezzo in Urkunden: Gustav Ehrismann, Geschichte der deutschen Literatur bis zum Ausgang des Mittelalters, II.1, Handbuch des deutschen Unterrichts an höheren Schulen, 6 (1922), S. 44.

${ }^{34}$ Mit diesen präzisen Angaben dürfte der Text wenn nicht auf eine 'Stiftungsnotiz' (Hugo Kuhn, "Eine Stiftungsnotiz für ein deutsches Lied," Text und Theorie [1969], S. 158-166), so doch "auf authentische Tradition zurückgehen" (Vollmann-Profe [Anm. 17], S. 34) und keinen "Quellenwahrheitsbeweis" (Heinz Rupp, Deutsche religiöse Dichtungen des 11. und 12. Jahrhunderts: Untersuchungen und Interpretationen, 2. Aufl. [1971], S. 82) bieten; doch ist die Posteriorität der Strophe und ihre Differenz zum Kontext (Sprecherposition) unverkennbar.

35 Vollmann-Profe (Anm. 17), S. 35.

${ }^{36}$ Kuhn (Anm. 34), S. $165 \mathrm{f}$.

37 S. die bekannte Klage Meinhards, des Rektors der Bamberger Domschule: Semper ille Attilam, semper Amalungum et cetera id genus portare retractat; Carl Erdmann, "Fabulae curiales: Neues zum Spielmannsgesang und zum 'Ezzo-Liede," ZfdA, 73 (1936), 87-98; Ergänzung: ZfdA, 74 (1937), 116. 
versuchte, ${ }^{38}$ wird sie in der Vorsatzstrophe explizit; und Konsequenz erhält damit im Hinblick auf den konstatierten Erfolg des Liedes, eine vil ware rede (V 14), auch die Erweiterung der Hörerschaft über Standesgrenzen hinaus.

Nicht erst diese spätere Spiegelung einer literarischen Entstehungssituation zeigt das Bestreben der volkssprachlichen Literatur, auf Lebenswelten Bezug zu nehmen. Schon die mit dem Ur-Ezzolied etwa zeitgleiche Wiener Genesis erweitert das erzählerische Spektrum durch die ausführliche Darstellung von Gefühlen, und die etwas spätere Exodus (1120-30) stellt in der bekannten Umdeutung von Kröten und Heuschrecken (der ägyptischen Plagen) als unritterliche bzw. ritterliche Heere Verbindungen zum Erfahrungsraum seiner intendierten adligen Zuhörerschaft her. ${ }^{39}$ Das sogenannte Merigarto, vielleicht um 1070 in Kloster Prül bei Regensburg entstanden, ${ }^{40}$ führt sogar einen Exilautor vor, der in eigener Sache spricht und zur Untermauerung seiner Islandschilderung auf persönliche Berichterstattung verweist; ${ }^{41}$ gerade angesichts der Darstellung des Wunderbaren (vor allem außerordentlicher Gewässer) geschieht hier ein "Schritt hin zu subjektiver Welterfahrung," ${ }^{42}$ wird die topische Wahrheitsbeteuerung in der Unmittelbarkeit der Ichaussage, des Erfahrungsberichts aufgebrochen und rückt so auch das Verhältnis von Literatur und Leben in den Blick.

Einen anders gearteten Reflex der Historizität von Literatur bietet das Annolied, wohl wenig nach dem Ur-Ezzo im Schnittpunkt klerikaler, reichsgeschichtlicher und städtischer Interessen entstanden $(1077-1081),{ }^{43}$ dessen Prolog die

\footnotetext{
${ }^{38}$ Genauer jetzt bei Ferdinand Urbanek, "Das 'Ezzolied' in den Traditionen von 'ars rhetorica' und germanisch-heimischer Redekunst," ZfdPh, 106 (1987), 321-340; 107 (1988), 26-48, der in Tl. 2 anhand von Langzeilenstruktur, asyndetischer Parataxe und Worten germanischer Provenienz die zur rhetorischen Gelehrsamkeit hinzukommende germanische Schicht im Ezzolied aufdeckt, dieses damit insgesamt im Schnittpunkt und als Abglanz zweier Traditionen - germanische Heldensage (Gunther) und ausgefeilte ars rhetorica (Meinhard) - situiert.

${ }^{39}$ Vollmannn-Profe (Anm. 17), S. 88ff.; Exodus (Papp [Anm. 31]), V. 1339-62 (Kröten) und 2162-80 (Heuschrecken).

${ }^{40}$ Norbert Th. J. Voorwinden, Merigarto: Eine philologisch-bistorische Monographie, Germanistisch-anglistische Reihe, 11 (1973), S. 125f.; Handschrift: 1. Viertel des 12. Jh.s (Hellgardt [Anm. 25], Nr. 101).

${ }^{41}$ Str. 11-13,2: Ih was $z$ 'Uztrehte in urliugeflubte, / want wir zwene piskoffe hetan, die uns menigiu lere tatan. / duo nemaht ih heime wese, duo skuof in ellente min wese. / Duo ih z'Uztriehte chwam, da vand ih einin vili guoten man, / den vili guoten Reginpreht. er uopte gerno allaz reht. / er was ein wisman so er gote gizam, / ein erhaft phaffo in aller slahte guote. / Der sagata mir ze wara, sam andere gnuogi dara, / er ware wile givarn in Islant,...

42 Vollmann-Profe (Anm. 17), S. 82.

${ }^{43}$ Für die nicht auszuschließende, aber insgesamt weniger plausible spätere Datierung (nach 1105) ist zuletzt ausführlich eingetreten Anselm Haverkamp, Typik und Politik im 'Annolied': Zum 'Konflikt der Interpretationen im Mittelalter' (1979), S. $79 \mathrm{ff}$. Zur Interessenbildung Vollmann-Profe (Anm. 17), S. 36-39.
} 
darzustellende Welt- und Heilsgeschichte vor dem Hintergrund allgemein geläufiger Heldendichtung präsentiert: ${ }^{44}$

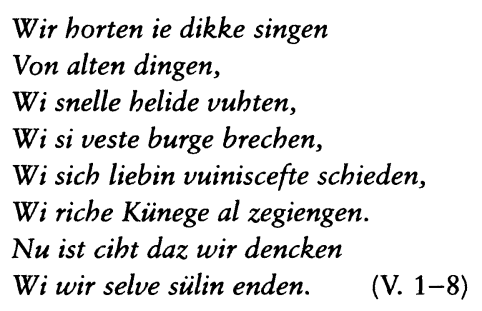

Diese ist verstanden als Medium vielfältiger Vergangenheitsbildung, insbesonders als Ausdruck der Vergänglichkeit der Dinge, des veränderlichen Weltlaufs mit dem Wechsel und Untergang von personalen Beziehungen wie Königreichen. Profane Literatur und Sinnorientierung sind damit - entgegen geläufigen Dichotomisierungen von weltlicher und geistlicher Literatur - nicht negativ beurteilt, ${ }^{45}$ erscheinen jedoch als eindimensional gegenüber der auf die Zukunft gerichteten Besinnung der christlichen Gemeinschaft, d.h. hier gegenüber der von Anno zeichenhaft vorgelebten Erwartung von Heil und Erlösung. Die topische Eingangswendung als Einstimmung des Publikums und Aufruf gemeinsamen kulturellen Wissens ${ }^{46}$ wird zugleich allerdings schillernd mit dem Fortgang des Textes: denn der weltgeschichtliche Teil des Annoliedes (Str. 8-33) erzählt ja gerade vom Aufstieg und Fall der Imperien, vom Kampf guoter helide, dem Aufbau und der Zerstörung von Burgen und Städten, um schließlich in den individuellen und gleichermaßen exemplarischen Heilsweg einzumünden. ${ }^{47}$ Nicht nur im Wortschatz schließt der Autor vielleicht an einheimische Heldendichtung an, ${ }^{48}$ er integriert diese in ein heilsgeschichtliches Programm, das Vergangenheitsbildung als Erfahrungsmedium in einem durch die Gegenwart hindurchgreifenden Prozeß der Transzendierung und typologischen Erfüllung begreift.

Dieser knappe, aber programmatische Ausgangspunkt wird - bei Kenntnis des Annoliedes - aufgegriffen in der Kaiserchronik, im zweiten Jahrhundertdrit-

44 Anno-Lied, hrsg. Martin Opitz MDCXXXIX. Diplomatischer Abdruck besorgt von Walther Bulst, Editiones Heidelbergenses, 2 (1946). Zum Eingang Gerhaher (Anm. 21), S. 1-11 u. ö.

45 S. zuerst Eberhard Nellmann in seinem Kommentar zur Ausgabe: Annolied, hrsg., übersetzt und kommentiert, reclam, 1416, 2. Aufl. (1979), S. 75.

46 Im Sinne des tua res agitur; s. Quintilian, Institutio oratoria, hrsg. Ludovicus Radermacher (1907), IV.1, 33; Heinrich von Veldeke, Eneasroman. Nach dem Text von Ludwig Ettmüller ins Neuhochdeutsche übersetzt, mit einem Stellenkommentar und einem Nachwort von Dieter Kartschoke, reclam, 8303 (1986), V. 1: Ir habet wol vernomen daz, /...

47 S. a. George Gillespie, "Spuren der Heldendichtung in Texten des 11. und 12. Jahrhunderts," Studien zur frübmbd. Lit. (Anm. 18), S. 235-263, hier S. $237 \mathrm{f}$.

48 Ebd., S. 238. 
tel, ${ }^{49}$ nun aber zu weit ausdrücklicheren Abgrenzungen vorangetrieben. Ausführlich wird hier im Prolog die Relation zwischen Vergangenheit, Gegenwart und Zukunft, die Rolle der Literatur im Rahmen von Geschichte und Heilsgeschichte thematisiert - auf der Basis einer Sprechhaltung, die sich eingebettet weiß in die allumfassende göttliche minne und diese als unbedingte Voraussetzung des Dichtens versteht. Der Sprecher wendet sich zunächst gegen die tumben, die sich, indem sie die Mühe der Einsicht und Vervollkommnung scheuen, ${ }^{50}$ als unnuzze erweisen und den Möglichkeiten literarischer Vermittlung (von wistuom unt êre, V. 13) verschließen; und wendet sich nach einer Vorstellung der intendierten Papst-Kaiser-Chronik ${ }^{51}$ auch gegen die zeitgenössische literarische Mode, Geschichten zu ersinnen, die, ohne Wahrheit des Stoffes fingiert und spielmännisch zusammengestellt, der Legitimation aus göttlicher Gnade heraus entbehren und dadurch nur ins Verderben führen können:

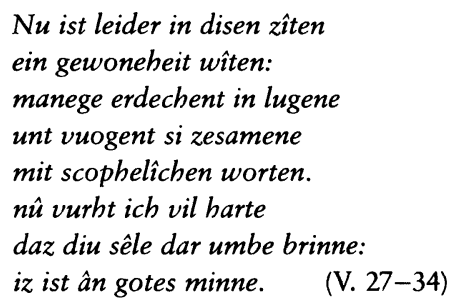

Worum es sich bei diesen 'lügenhaften' Geschichten ${ }^{52}$ gehandelt hat, die zu hören oder vorzutragen andernorts sogar als sündhafte Handlung eingestuft und in den Beichtkatalog eingefügt wurde, ${ }^{53}$ bleibt heute weitgehend im Dun-

\footnotetext{
49 Kaiserchronik, hrsg. Edward Schröder, MGH Dt. Chroniken, I, 1 (1892).

${ }^{50}$ V. 6-8: die tumben dunchet iz arebait, / sculn si iemer ibt gelernen / od ir wîstuom gemêren.

${ }^{51} \mathrm{Ob}$ die Verse 15-26 ursprünglich oder Zutat des ersten Fortführers und Bearbeiters der Chronik sind, spielt hier und angesichts der geringen zeitlichen Differenz zwischen den möglichen frühen Entstehungsstufen keine Rolle. Den sinnvollen Gehalt der Verse im Kontext hat Friedrich Ohly (Sage und Legende in der 'Kaiserchronik': Untersuchungen über Quellen und Aufbau der Dichtung, Forschungen zur deutschen Sprache und Dichtung, 10 [1940], S. 33f.) deutlich gemacht; von einem "offenbar ... später hinzugefügten Mittelteil” (Kartschoke [Anm. 17], S. 359) zu sprechen, scheint mir zu stark - eine Differenz der Sprecherpositionen besteht in dieser Deutlichkeit (ebd.) nicht.

52 Zur Diskussion um den Begriff scophelich Wilhelm Wissmann, Skop, Sitzungsber. d. Deut. Akademie d. Wiss. Berlin, Kl. für Sprache, Literatur und Kunst, 1954/2 (1955). In anderen Texten scheint dagegen eher eine Integration volkssprachlicher Mündlichkeit intendiert gewesen zu sein; s. das Auftreten des Erzählers im Duktus des Sängers (Wiener Genesis [Smits, Anm. 31], V. 3418: chunde wir ... scophen) und den sog. Scopf von dem lône (Waag/Gernentz [Anm. 17], S. 116-125).

${ }^{53}$ Bamberger Glaube und Beichte (Text nach der Münchener Handschrift, 12. Jh., in Deutsche Sagversdichtungen des IX.-XI. Jabrhunderts, hrsg. Eduard Sievers, Germanische Bibliothek, II, 16 [1924], Nr. 37), V. 210-212: In lugiságilon, in lugispéllen, / in buorlieden, in állen scantsángen, / in hónreden mánigen.
} 
keln. An Heldenepisches ist zu denken, auch an Vorstufen des König Rother oder Herzog Ernst als noch in der Mündlichkeit lebende Kurzepen von Brautgewinnung bzw. Vasallenempörung. ${ }^{54} \mathrm{Daß}$ der Autor im Kontext des Chronikprologs nicht wie Meinhard von Bamberg (s. Anm. 37) die anvisierte volkssprachliche Dichtung beim Namen nennt, wird plausibel, wenn es um die Ablehnung 'literarischer' Tendenzen im grundsätzlicheren Sinne gehen sollte, um die Ablehnung sowohl ihrer Themen wie ihrer Formen. Im Hintergrund steht wohl die aus klerikaler Perspektive gesetzte Antinomie von Mündlichkeit und Schriftlichkeit, nicht aber der "Überlieferungsprozeß von Mund zu Mund, von Generation zu Generation" ${ }^{55}$ generell. Die Polemik dient nicht zuletzt der Profilierung des eigenen, aufwendigen Werkes. ${ }^{56}$ Leitender Gesichtspunkt der Differenzierung ist die Dimension der Zeitlichkeit: während die dem Seelenheil förderliche Geschichte, d.h. das hier im Hinblick auf lateinische Gattungstradition programmatisch als crônicâ bezeichnete Werk, ${ }^{57}$ ein Hineinreichen der Vergangenheit in die eigene Gegenwart demonstriert, ${ }^{58}$ erstellt das nicht heilsgeschichtlich wahrhaftige Werk eine falsche Kontinuität, die erst in der nächsten Generation voll zum Austrag kommt:

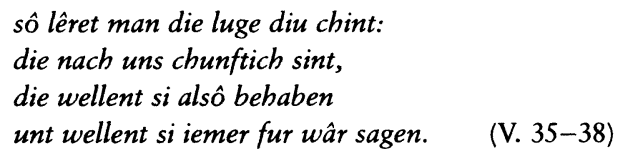

Das klingt zunächst, als hätte der Autor bei den mit scophelîchen worten gefügten Geschichten solche im Auge, die aufgrund ihrer Ein- und Zugänglichkeit gerade bei einem jungen Publikum auf offene Ohren stoßen ${ }^{59}$ - phantastische Stoffe von Helden, Liebe und Abenteuer, im Weltlichen bleibende Identifikationsangebote für empfängliche Gemüter in sozial instabiler Situation. ${ }^{60}$

${ }^{54}$ S. anhand des König Rother Walter Haug, "Struktur, Gewalt und Begierde: Zum Verhältnis von Erzählmuster und Sinnkonstitution in mündlicher und schriftlicher Überlieferung," Idee - Gestalt - Geschichte: Festschrift Klaus von See, hrsg. Gerd Wolfgang Weber (1988), S. 143-157.

ss Christian Schmid-Cadalbert, "Mündliche Traditionen und Schrifttum im Mittelalter," $A B a ̈ G, 21$ (1984), 85-114, hier 101.

56 Vergleichbar ist in diesem Sinne die Polemik Chrétiens in seinem Erec-Prolog (Erec und Enide von Christian von Troyes, hrsg. Wendelin Foerster [1890], V. 19-22: “d'Erec, le fil Lac, est li contes, / que devant rois et devant contes / depecier et corronpre suelent / cil qui de conter vivre vuelent."

57 Klaus Düwel, Werkbezeichnungen der mittelhochdeutschen Erzäblliteratur (1050-1250), Palaestra, 277 (1983), S. 11.

${ }^{58}$ Berichtet wird von den Kaisern, die vor uns wâren / unt Rômisces rî̀ches phlâgen / unze an disen hiutegen tac (V. 21-23).

59 Ohly (Anm. 51), S. 31: "im Schulunterricht ... verderblich"!

${ }^{60}$ So etwa Uberlegungen bei Peter K. Stein, die 'märchenhafte' Dietrichepik als eine Art von 'Erziehungsprogramm' zu verstehen (“'Virginal': Voraussetzungen und Umrisse eines Versuchs," Jabrbuch der Oswald von Wolkenstein Gesellschaft, 2 [1982/83], 61-88); 
Wichtiger ist aber wohl die damit angesprochene Frage nach der Wahrheitsbildung im Prozeß der Geschichte: gefordert ist implizit eine Differenzierungsleistung von gegenwärtigen Rezipienten, die in der Scheidung von Falschem und Richtigem, von heilsgeschichtlich Wertlosem und Werthaftem die Grundlage für das Wahrheitsverständnis der nächsten Generationen legen; denn diese werden ihrerseits das Überlieferte als Wahrheit erachten und weitergeben.61 Der Blick auf die Wiederholungen der Zukunft macht somit die Wichtigkeit gegenwärtiger Besinnung eindringlich; erst nach dem Aufzeigen der Gefahren, die für Erzähler wie Zuhörer von zweifelhaften Geschichten lauern, kann das anvisierte Publikum positiv gefaßt werden, erhält die anfangs abgelehnte Hörerschaft ihren begrifflichen Gegenpart: offenbaren sich die tumben durch Mißachtung der 'rechten' Geschichte, so zeichnen sich die wîsen gerade durch die Abkehr von falschen Erzählungen aus. ${ }^{62}$

Mehrfache Oppositionen - auf Produzenten- wie Rezipientenebene, Autor/ Erzähler wie Publikum betreffend - strukturieren den Prolog und skizzieren die Ausgangsbasis für eine Erzählung, die selbst in weiten Zügen von einem Gegensatz - dem zwischen guten und schlechten römischen Kaisern - berichten wird. Damit ist nicht nur die Frage von Geschichtlichkeit schlechthin, der Vermittlung des Gewesenen an das Zukünftige, in einer über das Annolied weit hinausgehenden Deutlichkeit gestellt, es treten auch Produzent, Text und Rezipient als aufeinander bezogene Kategorien 'literarischer Vermittlung' in den Blick. Literatur als Akt geistiger Arbeit profiliert sich in der Absetzung von müßiggängerischer Kurzsicht und reiner Fiktionalität. Daß die Kaiserchronik dabei selbst mündliches Erzählgut aus eben jenen Stoffbereichen integriert, die mit der Polemik gegen scophelîche worte abgelehnt worden waren, macht das Problem deutlich, eine volkssprachliche Erzählliteratur mit geistlichem Anspruch zu etablieren und sich zugleich an den Kenntnis- und Erwartungshorizonten des Publi-

zur Auseinandersetzung mit Georges Duby und seinem (in Frankreich) wirkungsreichen Versuch, die juvenes, nachgeborene und vom Familienerbe ausgeschlossene Adelssöhne des 12. Jahrhunderts, als wesentliche Trägerschicht der ritterlichen Literatur zu begreifen, s. jetzt Ursula Peters, "Von der Sozialgeschichte zur Familienhistorie: Georges Dubys Aufsatz über die Jeunes und seine Bedeutung für ein funktionsgeschichtliches Verständnis der höfischen Literatur," PBB, 112 (1990), 404-436.

${ }^{61}$ Das für die gemeinsame Position, den Zusammenschluß von Autor/Erzähler und Publikum wichtige die nach uns chunftich sint hat der Verfasser des Trierer Silvester (Handschriftenfragment Ende des 12. Jh.s; Hellgardt [Anm. 25], Nr. 185; hrsg. Carl Kraus, MGH Dt. Chroniken, 1,2 [1895]), der den Kaiserchronik-Prolog bekanntlich mit Ausnahme der 'chronikalischen' Passage (s. Anm. 51) weitgehend übernahm, zu nach in (V. 21) geändert.

${ }^{62}$ Signifikant ist die Begriffswiederholung, die das jeweils in der Negation Definierte zusammenhält: die tumben ... ungerne hôrent sagen (V. 6/11) - die wîsen ungerne der von sagen (V. 41). 
kums zu orientieren. ${ }^{63}$ Die durchgängige Berufung auf die Wahrheit des buoches spiegelt dieses Problem ebenso wie die Auseinandersetzung mit offensichtlich kursierenden anderen Versionen - nicht zufällig im Falle der Dietrichgeschichte, wo die abwertende Einschätzung falscher Überlieferung als luge (V. 14187) aufgegriffen wird. ${ }^{64}$

Gefordert ist somit das zielgerichtete, nämlich heilsorientierte Differenzierungsvermögen eines Publikums nach dem Vorbild der wîsen, eines Publikums, das nur wie in den meisten Texten der Zeit als christliche Gemeinschaft angesprochen wird; ${ }^{65}$ eine soziale Elite, wie in den herron der älteren Version des Ezzoliedes, scheint nur vereinzelt dort durch, wo die Kaiserchronik Züge eines Fürstenspiegels annimmt, ${ }^{66}$ doch ist angesichts des Anspruchs und Umfangs des dichterischen Unternehmens wohl an eine mit literarischen Traditionen nicht ganz unvertraute Hörerschaft an einem größeren Hof (Regensburg) zu denken. Einzugliedern ist die Kaiserchronik, die sich selbst im Prolog als liet (V. 42) und crônicâ (V. 17) bezeichnet, einerseits in das zunehmend deutlicher hervortretende Spannungsfeld zwischen der Vermittlung kirchlich-religiöser und didaktischer Normen und den Erzählansprüchen der an Ausdrucksmöglichkeit gewin-

${ }^{63}$ Am klarsten vielleicht in der Lucretia-Episode mit der heroischen Stilisierung von Lucretias Gatten als "Recken in der Fremde" (Haug [Anm. 6], S. 69f.) und in der Dietrich-Episode: Dietrich, immer wieder als helt lussam (V. 13932), helt guot (V. 14097) und wîgant (V. 14135) präsentiert, kann zur ritterlichen Identifikationsfigur werden (s. Joachim Knape, "Zur Typik historischer Personenerinnerung in der mittelhochdeutschen Weltchronistik des 12. und 13. Jahrhunderts," Geschichtsbewußtsein in der deutschen Literatur des Mittelalters, hrsg. Christoph Gerhardt, Nigel F. Palmer und Burghart Wachinger [1985], S. 17-36, hier S. 24), um schließlich in Übereinstimmung mit der ganzen klerikalen Tradition doch in die Hölle zu fahren (s. Ohly [Anm. 51], S. 222f.). Im Zusammenhang mag er damit als Exempel dienen, "welche Folgen es haben kann, wenn die Kaisermacht in falsche Hände gerät" (Karl Stackmann, "Dietrich von Bern in der 'Kaiserchronik': Struktur als Anweisung zur Deutung," Idee-Gestalt-Geschichte [Anm. 54], S. 137-142, hier S. 141).

${ }^{64}$ Vgl. 14176ff.: Swer nû welle bewaren, / daz Dieterîch Ezzelen saehe, / der haize daz buoch vur tragen. / ...; s.a. Otto Gschwantler, "Zeugnisse zur Dietrichsage in der Historiographie von 1100 bis gegen 1350," Heldensage und Heldendichtung im Germanischen, hrsg. Heinrich Beck, Ergänzungsbände zum Reallexikon zur Germanischen Altertumskunde, 2 (1988), S. 35-80.

${ }^{65}$ Vgl. V. 26: iz verneme swer der welle; s.o. Anm. 26. Meist wird das Publikum nur wie auch in der Predigt (s. Ganz [Anm. 126], S. 69, Anm. 52) als ir lieben (lute) (lat. carissimi, dilectissimi) apostrophiert; etwa Wiener Genesis (Smits [Anm. 31]), V. 133; Vom Himmelreich (Waag/Schröder [Anm. 17], I, 92-111), V. 144; Adelbrecht, Johannes Baptista (Maurer [Anm. 17], II, 328-341), 17, 1, V. 225; Jüngere Judith, hrsg. Hiltgunt Monecke, ATB, 61 (1963), V. 1; Leben Christi, hrsg. Franz Pfeiffer, ZfdA, 5 (1845), 17-32, V. 86.

${ }^{66}$ V. 5679-82: von diu suln alle kunige / bî im iemer nemen pilede, / behuoten ir sêle, / behalten ouh werltlîch êre; V. $6083 \mathrm{ff} .:$ Nû suln alle werltkunige / dâ bî nemen pilede / wi der edel kaiser Trajân /... 
nenden Texte, andererseits in den Prozeß der Öffnung volkssprachiger Literatur für Stoffbereiche abseits von biblischer, heilsgeschichtlicher oder paränetischer Grundlage und Funktionalisierung.

Die Linie der Auseinandersetzung mit anderen literarischen Traditionen, mit falschen Erzählungen und Zuhörern, mit Neidern und Kritikern ${ }^{6}$ läßt sich zunächst noch über Annolied und Kaiserchronik hinaus verlängern. In der Beschreibung des himmlischen Jerusalem (um 1140), vollständig nur in der Vorauer Sammelhandschrift vielleicht als eine Art visionären Ausblicks überliefert, verbindet sich die anfängliche Frontstellung gegen Kritiker mit der am Ende vorgenommenen Polarisierung von geistlicher und weltlicher Literatur. So fürchtet der Autor zunächst Schelte angesichts seiner ehrgeizigen (gleichwohl durch eine lateinische Quelle abgesicherten) Schilderung, angesichts seiner mit tifen gesinnen (V. 2) begonnenen Allegorese, ${ }^{68}$ um schließlich doch deutlich den heilsgeschichtlichen Nutzen seiner Erzählung gegenüber tumben Zuhörern (V. 448), gegenüber Geschichten/Gesängen von werltlichen dingen / unt von der degenhaite (V. 450f.) abzugrenzen. Er setzt sich ab von "Helden- oder historische[n] Ereignisliedern," ${ }^{69}$ wie eine Generation später dann auch der Dichter des Linzer Antichrist (um 1170), der in eschatologischer Perspektive, in Anlehnung an ein prophetisches Pauluswort den auf falsche spellir unt niwe moere Fixierten die gewissenhaft an die Endzeit Denkenden (Str. 2) entgegenstellt. ${ }^{70}$ Im Himmlischen Jerusalem folgt auf die zitierten Verse noch eine aus geistlicher Tradition bekannte Metaphorik der zwei Wege, des breiten zur Hölle und des schmalen in den Himmel führenden, ${ }^{71}$ eine Metaphorik, die die Polarität zwischen Verdammnis und Heil veranschaulicht, in der Parallelstellung zur Polarität guoter und schlechter rede aber zugleich ein Bewußtsein der Prozessualität des Erzäh-

${ }^{67}$ Stellen aus lateinischen und deutschen Texten bei Schwietering (Anm. 20), S. 164-167; Literatur zur Geschichte dieses seit Hieronymus in der christlichen Literatur begegnenden Topos bei Haug (Anm. 6), S. 56, Anm. 10.

${ }^{68}$ Himmlisches Jerusalem (Waag/Schröder [Anm. 17] I, 92-111), V. 18-20: vile harte vorhte ih mir des, / daz eteliche scelten: / von den himelen rede wir selten. Uber die lateinische Quelle Christel Meier, “Zur Quellenfrage des 'Himmlischen Jerusalem': Ein neuer Fund," ZfdA, 104 (1975), 204-243.

${ }^{69}$ Kartschoke (Anm. 17), S. 312.

${ }^{70}$ II Tim, 4,3f.: "erit enim tempus cum sanam doctrinam non sustinebunt / sed ad sua desideria coacervabunt sibi magistros / prurientes auribus / et a veritate quidem auditum avertent / ad fabulas autem convertentur"; Linzer Antichrist (Maurer [Anm. 17] III, S. 361-427), Str. 1 (V. 1-10): Wir han zehant daz zit, / von dem Paulus sus kit: / "ir orin kerint sie von der warheit, / nüziu rede ist in leit. / spellir unt niwe mare, / sin si joch ungeware, / horint si allir gernist. / keinen frumin ernist / megin si ze gote han, / die des niut wellint abegan."

${ }^{71}$ Zur Geschichte des Wegmotivs seit Hesiod J. Schmid, “Weg," LThK, X, 2. Aufl. (1965), 974-976. 
lens andeutet; der Weg der Erzählung kann analog zum aufgezeigten Weg ins himmlische Jerusalem erscheinen. ${ }^{72}$

Ausführlich ist die Auseinandersetzung mit Spöttern und Kritikern in der Jüngeren Judith der gleichen Vorauer Handschrift. Daß der Autor die Geschichte des mutigen, gottgelenkten Widerstandes einer einzelnen Frau, einer prototypischen praeclara virgo, ${ }^{73}$ gegen den im Namen Nebukadnezars kämpfenden Feldherrn Holofernes, die Geschichte, wie Gott sein Volk beschirmôte mit einem blôden wîbelîn (V. 28), als rede vil wunnesame (V. 3) ankündigt, kann angesichts eines mit den exegetisch-typologischen Variationen der JudithGestalt nicht vertrauten Publikums kaum verwundern; der nach heldenepischen Mustern gestalteten ersten deutschen Bearbeitung des Stoffes, der in der Vorauer Handschrift vorausgehenden Älteren Judith, steht im jüngeren Text eine episch breite, belehrende Fassung zur Seite, die das Unglaubliche des in Gestalt Judiths, der frommen und schönen Witwe, Gewirkten in einen exemplarischen Heilsakt aufhebt. ${ }^{74}$ Die Auseinandersetzung mit Neidern und Spöttern im Prolog wird damit zum Paradigma für den allgemeinen Gegensatz von Heil und Unheil, in der Geschichte repräsentiert durch Judith und Nebukadnezar. ${ }^{75}$ Denjenigen, die aus purer Negativität ehrenhafte Versuche und nützliche Lehre in Frage stellen, wird ein entsprechend übles Ende, der Verlust des Seelenheils prophezeit:

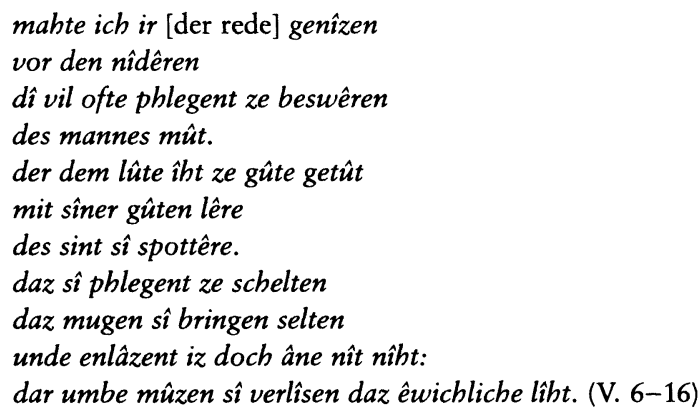

Ähnlich ist das Diktum über ungünstig Gesinnte auch bei Wernher und dem Wilden Mann, hier allerdings vor konkreterem Hintergrund. Für die dreigeteilte Mariendichtung des phaffen Wernher hat man das seltene Glück, Entstehungs-

72 V. $443 \mathrm{f} .: \mathrm{Nu}$ habent ir alle wol vernomen, / wi ir in die burch sculet chomen. Zur Wegmetaphorik s. weiter unten anhand des Anegenge.

73 S. Naumann (Anm. 26), S. 67, der umfassend die mittelalterlichen Sinnhorizonte des Judithstoffes und ihre Präsenz in lateinischen und den beiden deutschen Texten darstellt.

${ }^{74}$ Jüngere Judith (Monecke [Anm. 65]), V. 17-19: Ich wil $\hat{u}$ sagen von unserm heilêre, / wî manige lêre / er uns vore hât getragen, / . .

75 S. Haug (Anm. 6), S. 56. 
datum (1172) und -umstände zu kennen. ${ }^{76}$ Der Marienpreisprolog greift hier zunächst mehrfach auf die topische Bitte um Inspiration und Kraft zur Durchführung des Werkes zurück, ${ }^{7}$ schiebt aber auch eine ausführliche Erklärung zur Entstehung der lateinischen Vorlage (eine nicht genau bekannte lateinische Version des Evangeliums des Pseudo-Matthäus) ein, die das eigene Unternehmen historisch-soteriologisch legitimiert. ${ }^{78}$ Vor dem Beginn der Erzählung ist nochmals darauf zurückgegriffen - im Kontext einer Auseinandersetzung mit der vom Teufel beeinflußten unwirdischen (unuerwizzenen $\mathrm{D}$ ) diet, die es wagt, die Dichtung zu schelten (F 193f.). Das Resultat, das den Geiferern beschieden wird, ist das gleiche wie in der Jüngeren Judith, ${ }^{79}$ doch der Begründungshorizont ein anderer. Matthäus erscheint hier unhistorisch selbst als derjenige, der die manichäische Irrlehre des Leukios bekämpfte, ${ }^{80}$ der Sieg der rechten Schrift, damit des Heils, bereits anhand der literarischen Kontroverse der Vergangenheit gesichert. Wer sich gegen diese Erzählung wendet, wendet sich zugleich gegen Matthäus, damit gegen die richtige christliche Lehre; ${ }^{81}$ während umgekehrt der Lehre des Hieronymus, des Übersetzers des Evangeliums zu folgen, zum Seelenheil führen wird - das ist die Perspektive, unter der das Publikum, Laien und besonders Frauen, ${ }^{82}$ in die Erzählung eintritt.

76 Priester Wernher, Maria. Bruchstücke und Umarbeitungen, hrsg. Carl Wesle, 2. Aufl. besorgt von Hans Fromm, ATB, 26 (1969); Angaben zur Entstehung im Epilog (C1 5799ff.): Jahr, Autorname, Auftraggeber Mangold (wohl Probst und später Abt des Benediktinerstifts S. Ulrich und Afra in Augsburg), Arbeitsumstände (C ${ }^{1}$ 5817-26: er ladete in in daz 〈sin > hûs / unt enliez in ouch niht dar $\hat{u} z$, / unz er gefrumete unt geriet / daz diu geistlichen liet / wurden gemachet. / do enwart nibt vil gelachet: / sante Marîe / diu gap in kurzewîle / unt... gez framspuote, / daz es si nibt enmuote.).

77 V. 1 ff., V. 45 ff. (Maria), F 187f. (D 185f.): mit der Hilfe des Hl. Geistes.

78 V. $77 \mathrm{ff}$.: Der Evangelist Matthäus habe von Christus geschrieben, aber auch von seiner Mutter; doch wurde diese Rede auf Anregung der Bischöfe Chromatius und Eliodorus erst durch Hieronymus aus dem Hebräischen ins Lateinische übertragen (daz wazzer wart da ze wîne, / div milch verwandelt sich in daz ole, D 94f.), von wo her ihre Wahrheit und Weisheit nun weiter ins Deutsche gelangt (V. $125 \mathrm{ff}$.).

${ }^{79}$ F 198-200: ich wâne den fluoch fur den segen / 〈si〉 von got enphâhent, / die sich daran vergâbent.

${ }^{80}$ Wesle (Anm. 76), große Ausgabe (1927), S. LVII; die Passage beruht auf einer Verzerrung der Angaben im Brief des Hieronymus an Chromatius und Eliodorus (Hieronymus, Epistolae, PL, 30, Sp. 297 [Nr. XLIX]), der zusammen mit dem folgenden (Nr. L: De Nativitate sanctce Maria) meist als Vorspann des Pseudo-Matthäus-Evangeliums tradiert wurde; s. Hans Fromm, Untersuchungen zum Marienleben des Priesters Wernher, Annales Universitatis Turkuensis, 52 (1955), S. 43.

${ }^{81}$ F 201f.: swer ditze liet bespreche, / Mathêus muoz ez rechen.

82 GFD 144; A 142: phaffen, layen, vrowen. Gegen Ende des zweiten Teiles werden die Frauen aufgefordert, das Lied abzuschreiben und zu verbreiten - die Ursprünglichkeit der Bemerkung läßt sich aufgrund der Überlieferung der Stelle allerdings nicht sichern (A 2557-66, C 3049-58). Vgl. Anm. 26. 
Der gleiche Gegensatz zwischen godis bulde und Heilsverlust steht auch im Hintergrund der Ausführungen über die girheit eines wohl aus dem Laienstand kommenden Autors, der sich selbst mehrfach als 'Wilder Mann' bezeichnet und die erhaltenen Texte vielleicht Ende der siebziger Jahre des 12. Jahrhunderts verfaßt hat. ${ }^{83}$ Spott, Kritik, Unaufgeschlossenheit gegenüber dem Heilsangebot werden von ihm anhand des Bildes vom in der Sonne zergehenden Reif als unbeständig gekennzeichnet ${ }^{84}$ und zugleich literarisch fixiert: nach der traditionellen, hier an den heilich engil gerichteten Bitte um göttlichen Beistand ${ }^{85}$ distanziert der Wilde Mann sein dichterisches Unternehmen von der unernsteren Form des Leichs, die der kathartischen Funktion entbehre, und verdeutlicht, welch andere Richtung die folgenden Worte nehmen sollen. ${ }^{86} \mathrm{Da}$ der Leich "als 'vanitas'-Dichtung schlechthin," als "unmoralische, nur ästhetische 'delectatio"” gekennzeichnet wird, ${ }^{87}$ dient nicht nur der Abgrenzung des eigenen, erzählerisch-heilsgeschichtliche Kontinuität erstrebenden literarischen Versuchs (gezeswe [zesamene] birichten, V. 4), sondern wohl auch einer Korrektur von Publikumserwartungen. Ähnlich wie im Annolied werden die mit bestimmten Formen volkssprachlicher Dichtung vertrauten Zuhörer auf einen neuen literarischen Ernst eingeschworen, auf ein Verständnis von Literatur weniger als Unterhaltung denn als Heilsmodell, wobei angesichts des Wilden Mannes auch eine Korrektur eigener dichterischer Vergangenheit im Spiel sein kann. ${ }^{88}$ Auch die zunächst topisch scheinende Auseinandersetzung mit ungünstig gesinnten $\mathrm{Zu}$ -

${ }^{83}$ Die Gedichte des Wilden Mannes, hrsg. Bernard Standring, ATB, 59 (1963), S. 31-43: Van der Girheit; s. Vollmann-Profe (Anm. 17), S. 186-188.

${ }^{84}$ V. 15-20: alse ist des spothers stedicheit / alse de rife, di da zugeit, / di indar der sunnen nit gibeiden. / nv wil ich uch warnen undi bireiden, / wi ir mugit ginesen undi sterben / undi ginesinde godis hulde irwerbin. Später noch einmal aufgenommen und wie in der Jüngeren Judith in eschatologischer Perspektive gebrandmarkt; V. $253 \mathrm{ff}$. (V. 255: rife; V. 262: sunni); V. 269 f.: in der helle legit he [der spotter] fundamunt, / des wirdit sin arme sele wnt.

${ }^{85}$ Deutlicher noch am Beginn der Veronica (Standring [Anm. 83], S. 1-21) mit dem Bekenntnis zu nicht buchgelehrter, unmittelbarer Inspiration durch den Heiligen Geist (aber ohne den sin-Begriff, mit dem Wolfram im Willehalm-Prolog eine in den Voraussetzungen ähnliche Situation entfalten wird).

${ }^{86}$ V. 6f.: want iz ist bezzir dan ein leg, / iz machit harde herze weich; V. 12-14: dar umbe sagin ich $v$ von deme leiche, / dat is niman mit spothe verste, / hene mirche, war duse rede ge.

${ }^{87}$ Hermann Apfelböck, Tradition und Gattungsbewußtsein im deutschen Leich: Ein Beitrag zur Gattungsgeschichte mittelalterlicher musikalischer "discordia", Hermaea, 62 (1991), S. 102.

${ }^{88}$ Vollmann-Profe (Anm. 17), S. 188; Schwietering (Anm. 20), S. 203f.; noch einmal an späterer Stelle, V. $161 \mathrm{ff} .:$ Di wilde man, di dit dibtet, / de is selue harde unbirichtit. / so wi iz idoch im irge, / ich wene, he ummer gese / undie di scharpen dorne, / al hat he bit zorne / harthe lange gilevit. / ... 
hörern und anderen literarischen Formen kann damit bereits individuelle Züge tragen..$^{89}$

Deutlich wird zugleich eine Konkretisierung literarisch-lebensweltlicher Bezüge, die etwa zur gleichen Zeit oder wenig später bei einem nicht zwingend lokalisierten Heinrich, dem sogenannten Heinrich von Melk, bereits höchste Blüten treibt. ${ }^{90}$ Er nennt wie Wernher seinen Gönner, hier einen Abt Erchenfried, im Epilog, ${ }^{91}$ gewinnt selbst aber Profil vor allem als pointierter Erzähler und begnadeter Satiriker: in der Geißelung der sehr weltlichen Gelüste der Priester nach Frauen und Wohlleben, in der drastischen Schilderung körperlichen Zerfalls nach dem Tode anhand der fiktiven Exempelerzählung von einem Königssohn, der seinem eigenen herangewachsenen Sohn noch einmal aus dem Grabe und der Hölle heraus erscheinen kann; ${ }^{22}$ vor allem aber in der Ironisierung der Rede, im sehr bewußten Spiel mit Uneigentlichem und Unmöglichem, in einem auch für spätere Zeit noch erstaunlichen 'Autorbewußtsein.' Heinrich spielt mit Erwartungshorizonten, ${ }^{93}$ mit dem hypothetischen Charakter einer Jenseitsvision, ${ }^{94}$ dem Konstitutionsakt der Erzählung, ${ }^{95}$ schließlich sogar mit dem Problem der eigenen Digressionen; ${ }^{96}$ und gewagt mutet es an, wenn er sich im Priesterleben für den Fall, daß er die Wahrheit verfehlt haben sollte,

89 Der Topos lebt noch im Prolog zum Tristrant Eilharts von Oberge (hrsg. Franz Lichtenstein [1877]; überliefert nur in den jüngeren Handschriften D und H) fort, wo die, deren herze sô gar krank is (V. 15), gescholten und verwarnt werden, gemahnt sich ruhig zu verhalten und der Bosheit eine Weile zu entsagen; doch der normative Horizont fehlt, um den eigenen Ansprüchen Nachdruck zu verleihen - nur als sinnenlos (V. 26f.) können Störenfriede eingestuft, nicht aber verurteilt werden.

90 S. a. Vollmann-Profe (Anm. 17), S. 166-171; Kartschoke (Anm. 17), S. 382-387.

91 Von des todes gehugde (Maurer [Anm. 17], III, 328-359), V. 1033. Daß die verschiedenen, früher Heinrich von Melk zugeschriebenen Texte hier im Hinblick auf verschiedene Merkmale zusammenhängend behandelt werden, ist nicht als Votum für eine Autorschaft zu verstehen (Vollmann-Profe [Anm. 17], S. 166: "das letzte Wort in dieser Frage noch nicht gesprochen").

92 Von des todes gehugde, V. 511f./913: Eines chuniges sun welle wir iu nennen, / ob ir an dem muget erchennen, / . . . / unt habe diz ze einem spelle; V. 597f./610-613: Nu gienc dar, wip wolgetan, / unt scowe dinen lieben man /... / nu sich, in wie getaner heite / diu zunge lige in sinem munde, / da mit er diu trutliet chunde / behagenlichen singen.

${ }_{93} \mathrm{~S}$. das manchmal zur Erklärung nachgeschobene ich mein (Priesterleben, V. 54, 118).

94 Von des todes gehugde, V. 690-695: nu gedenche an die sinne, / wie er dir antwurten solde, / ob ez der nature 〈re〉 bte verdolde, / oder ob sin got wolde verhengen. / ich wil die rede nibt lengen, / ich spriche furt in unt mit im.

${ }_{95}$ Von des todes gehugde, V. 516-521: wir mugen iu maniger slabte sache / hie ze stet lazzen under wegen, / da mit wir diu chint mobten biwegen / ze einer langen siecheite. / nu lazze wir in zuo der swertleite / mit allen vreuden volchomen.

96 Von dem gemeinem lebene (Maurer [Anm. 17], III, 302-327), V. 440-442: swa aber ich den orden han zebrochen / der materie, di ich ane viench, / daz machent lesterlichiu dinch. 
hinter das schützende Kreuz und Banner Christi zurückziehen will.97 Der Erzählakt wird hier selbst zum Abenteuer, und seine Durchbrechungen erzeugen ein irisierendes Spektrum von Interferenzen zwischen Heilsdidaxe, um die es ja immer geht, literarischer Vermittlung und Lebenswelt - meßbar schon im Priesterleben an der gleichzeitigen Apostrophierung von geistlichen Seelsorgern und laien, "so daß der Dichter gewissermaßen als der Sprecher der Laienschaft auftreten und die Laienschaft 'mithören' konnte, was in ihrem Namen gegen die Verweltlichung ihrer Priester vorgetragen wurde."98 Literatur zeigt sich hier jedenfalls als Medium, das sich aus dem reinen Dienst am göttlichen Wort und Heilsakt emanzipiert, nicht nur angesichts konkreter Lebenswelten, sondern auch eigengesetzlicher Dynamik.

In die gleiche Richtung geht die anspruchsvoll konzipierte heilsgeschichtliche Basisunterweisung, die ein unbekannter Geistlicher wohl ebenfalls im letzten Viertel des Jahrhunderts vornahm, in einem Werk, das in der gleichen Wiener Sammelhandschrift"9 tradiert ist wie die Texte des 'Heinrich von Melk': dem nach der Überschrift in der Handschrift so genannten Anegenge. ${ }^{100}$ Die auf das Verhältnis zwischen Mensch und Gott, die Themen von Schöpfung und Erlösung zentrierte Dichtung hat lange Zeit schlechte Noten in der Forschung bekommen, ${ }^{101}$ auch die Durchsetzung des Werks mit Reflexionen keineswegs nur immanenttheologischer Art erschien vor allem unter dem Zeichen mangelnder Einheit und Stringenz von Gedanke und Formung. Daß der Text zwischen Erzählung und theologischer Explikation schwankt, bedeutet jedenfalls nicht notwendig ein 'Ausweichen,' ${ }^{102}$ gehorcht vielmehr einer grundsätzlichen - verschieden gelösten - Problemstellung in der volkssprachlichen Vermittlung von

\footnotetext{
97 Priesterleben, V. 646-649: han aber ich die [warheit] iender zebrochen, / daz choem mir ze einem verlorne, / unt behuot mich vor iz zorne / Christes chriuze unt sin van.

${ }_{98}$ Vollmann-Profe (Anm. 17), S. 170f.; s. aber auch Priesterleben, V. 650: $n u$ sprech ouch wir 〈ir > irriu wip an.

99 Wien, ÖNB, cod. 2696 (um 1300), f. 165 $-178^{\mathrm{b}}$ : Von des todes gehugde, f. 179a-221 $1^{\mathrm{b}}$ : Anegenge, f. $303^{\mathrm{a}}-307^{\mathrm{b}}$ : Priesterleben.

100 Text: Anegenge, hrsg. Dietrich Neuschäfer, Altdeutsche Texte in kritischen Ausgaben, (1969).

${ }^{101}$ Ich zitiere nur aus den Schlußbemerkungen von Rupp (Anm. 34), der dem Text eine der gründlichsten Behandlungen hat zuteil werden lassen: dem Autor fehle die "dichterische Fähigkeit und die sprachliche Möglichkeit. Die Entstehung und Aufzeichnung seines Werkes ist nur zu erklären aus einer mangelnden Urteilsfähigkeit des Verfassers über sich selbst und aus einer Zeitsituation, in der Dichten zeitgemäß war, einer Zeit in der man glaubte, es seinem Publikum schuldig zu sein, seine Themen in Reimpaaren vorzutragen" (S. 217-260, hier S. 260). Differenzierend jetzt Vollmann-Profe (Anm. 17), S. 188; Kartschoke (Anm. 17), S. 276-279. Ausführlich zum Kontext des Sündenfalls Brian Murdoch, The Fall of Man in the Early Middle High German Biblical Epic: The 'Wiener Genesis,' the 'Vorauer Genesis' and the 'Anegenge,' Göppinger Arbeiten zur Germanistik, 58 (1972).

${ }_{102}$ Rupp (Anm. 34), S. 258 (verstanden als Ausweichen ins Erzählen).
} 
Heilswahrheiten an theologisch kaum Geschulte. Ich versuche wenigstens einiges unter nicht von vornherein wertender Perspektive anzudeuten.

Der Prolog beginnt traditionell, mit der bekannten Bitte um Sinnerfüllung und Inspiration, die parallelisiert ist zu dem häufig herangezogenen Wunder, das Jahwe an Bileams (Barlaams) Eselin wirkte, indem er diese zum Sprechen brachte; ${ }^{103}$ und in der Tat sind es grôziu dinc und wunderlîchiu maere / von unserm schephare (V. 34-36), die der Autor erzählen will. Doch ist mit diesem Unternehmen auch die Gefahr verbunden, sich zu weit vorzuwagen, schuldig zu werden wie derjenige, der etwas im Wege stehen ließ, an dem sich ein Blinder stößt, oder der, der einen Brunnen grub, in den ein anderer fällt (V. 41-47). Der Bildbereich, den die bibelnahen Wendungen evozieren, ${ }^{104}$ wird transparent für die Erzählung selbst: auch wer befürchte, daß der Autor zu tief graben wolle, solle sich dennoch getrost dessen Leitung überlassen, die um alle 'Schadensfälle' herumführen wird; ${ }^{105}$ wer aber weiter in die Tiefe göttlicher Geheimnisse vordringen wolle, falle aus der Verantwortung des Erzählens heraus, damit den eigenen Gedanken zum Opfer, falle - bildhaft - in den selbst gegrabenen Brunnen, um dort zu ertrinken (V. 56/88). ${ }^{106}$ Es sind wieder - wie in der Kaiserchronik - die tumben (V. 52), die nie Zufriedenen, Leichtfertigen, für Zweifelhaftes Anfälligen, die als Negativfolie herhalten: ${ }^{107}$ denn das göttliche Sein vor der Schöpfung (V. $61 \mathrm{ff}$.), das Wesen der Trinität (V. 66), das Böse, sein Wirken und seine Folgen bis hin zum limbus puerorum (V. $67 \mathrm{ff}$.) müssen als zutiefst verborgen angesehen werden, nur einem anmaßenden Denken, einem der Neugier und

\footnotetext{
${ }^{103} \mathrm{Nm}$ 22,22ff.; s.a. Il Pt 2,15f.; Belege bei Curtius (Anm. 9), S. 243 u. Anm. 3.

104 Das Bild des Blinden geht zurück auf Lv 19,14 ("non maledices surdo / nec coram caeco pones offendiculum"), das des Brunnens auf Ex. 21, 33 ("si quis aperuerit cisternam et foderit et non operuerit eam / cedideritque bos vel asinus in eam / dominus cisternae reddet pretium iumentorum...."); s. Valentin Teuber, "Uber die vom Dichter des 'Anegenge' benutzten Quellen," PBB, 24 (1899), 259-360, hier 250f. Das Brunnenbild ist in der Bibelexegese immer wieder als Zeichen der Verhüllung göttlicher Geheimnisse gedeutet worden; zur Metaphorik Hans-Jörg Spitz, Die Metaphorik des geistigen Schriftsinns: Ein Beitrag zur allegorischen Bibelauslegung des ersten christlichen Jahrtausends, Münstersche Mittelalter-Schriften, 12 (1972), S. 116 (Verbindung Brunnen-Schrift) und $209 \mathrm{ff}$.

105 V. 48-51: alle die nû dunche, / daz ich ze tiefe welle graben, / die wil ich gerne von dem schaden / leiten hin dannen baz.

106 S. im Rahmen der Polemik gegen die hurenden Geistlichen Priesterleben, V. 132-135: so leitet der blinde den blinden in die gruobe. / diu gruobe ist diu belle, [wörtlich Von dem gemeinem lebene, V. 259] / des aber got nibt enwelle, / daz iwer einer sich oder ander iemen dar in velle. Die gleiche Metaphorik des Grabens noch bei Michel Beheim in Zugweise Nr. 2 gotes wesen vor den geschephten (Gedichte, hrsg. Helmut Gille und Ingeborg Spriewald, Bd. I, DTM, 60 [1968], S. 5f.), V. 6: ein tumer lay sol graben nicht so tieff.

${ }_{107}$ Die Parallele zur Kaiserchronik scheint mir hier evidenter als die von Kartschoke (Anm. 17), S. 279 herangezogene zum Armen Hartmann, Rede vom Glauben (Maurer [Anm. 17], II, 569-628), der die Belehrung der tumben ("die weder Latein können noch geistlich gebildet sind") intendiert (V. 22) und sich selbst diesen zurechnet (V. 423).
} 
nicht der Wahrheitsliebe gehorchenden ervorschen (V. 60; aufgegriffen: V. 821) scheinbar zugänglich ${ }^{108}$ - im weiteren Text wird der Hinweis auf das 'Grundlose' und 'Unergründbare' leitmotivischen Charakter gewinnen. Zugleich ist mit dieser negativen Folie aber das Programm der Erzählung angegeben, sind die Themen genannt, die sodann im Vordergrund stehen werden. Das verweist weniger auf den "Hochmut des Gebildeten" 109 als auf die in Anspruch genommene Vermittlungskompetenz des Autors, nichtsdestoweniger bleibt der Kontrast zwischen der Abweisung eines Denkens, das sich über letzte Grenzen hinwegzusetzen sucht, und dem eigenen Erzählvorhaben, das eben diese Grenzen in den Blick nehmen wird, zunächst bestehen. Bereits der erste Exkurs knüpft hier an, verdeutlicht und mildert diesen Kontrast im Hinblick auf die grundlegende christliche Unterscheidung zwischen Denken und Glauben, zwischen dem, was begrenztem menschlichen Vermögen (sin) möglich ist, und dem mithilfe göttlicher Inspiration Erreichbaren (s. Bileam). Aller Zugang zu Gott, alle Mitteilung des Göttlichen durch den Menschen in Sprache und Rede kann nur bestehen aufgrund des vorgängigen Wirkens Gottes im trinitarischen Gnadenakt, der als Paradigma der Erfüllung, der Erhebung des Menschen dem Publikum vermittelt werden soll:

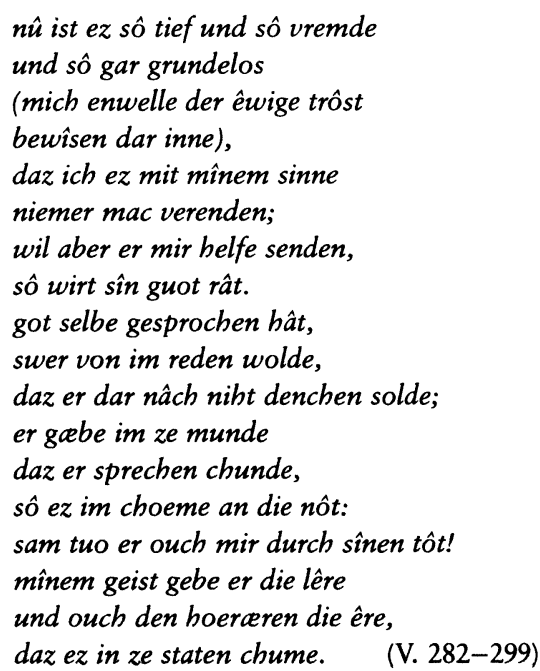

Der Eingang des Anegenge bietet mit der Reflexion des literarischen Aktes vor dem Hintergrund alttestamentlicher Metaphorik bemerkenswerte Perspektiven. Die Erzählung erscheint als sperriger Gegenstand am Weg, als Brunnen,

${ }^{108}$ Durchaus selbstbewußt formuliert dagegen Rupert von Deutz das Recht, "proprii vomere ingenii" Brunnen zur Weisheit zu graben; Spitz (Anm. 104), S. 114f. mit weiteren Belegen.

109 Rupp (Anm. 34), S. 218. 
als Hindernis für blind Umhertappende, die der Führung bedürfen; gefordert ist damit ein Erzähler, der zu lenken versteht, und ein Publikum, das sich nicht eigenmächtig vom Weg entfernt. Die Umsetzung von Bildsprache in literarische Situation ist dabei kaum ausdrücklich markiert und bleibt in manchem unscharf: die Geschichte, die rede, ist Prozeß und Gegenstand zugleich, Weg und Hindernis, Akt des Grabens und Loch in einem; der Sprecher vereint in sich die Haltung radikaler Demut mit Ansätzen eines Auftretens als bewußter Führer durch die Materie. Im Nebeneinander von Andeutung und Ausführung manifestiert sich nicht einfach das Scheitern angesichts einer anspruchsvollen Konzeption, vielmehr auch ein Reflex neuer Möglichkeiten, das Verhältnis von theologischem Anspruch und erzählerischer Verwirklichung in den Blick zu nehmen. Der Blick bleibt tastend, das Subjekt schließlich doch Sprachrohr Gottes; daß aber auch heilsgeschichtliches Kernland nur vermittelt als Erzählung und damit auf einem möglicherweise beschwerlichen Weg zugänglich ist, war eine Erkenntnis mit Folgen für den Fortgang des Werkes. Die Erzählung verschiedener Passagen aus der biblischen Genesis wird im weiteren immer wieder unterbrochen von der Auseinandersetzung mit abweichenden Meinungen und Irrlehren, die zugleich meist die Möglichkeit einer Literarisierung der Heilsereignisse ins Auge faßt. Die Frage nach dem Schmerz und der Furcht Christi am Kreuz, die nur ein bôser irrcere (V. 788) stellen kann, mündet in einen ausführlichen Unsagbarkeitstopos, den Erzähler präsentierend im Gefolge Salomons und als Jenseitsreisenden; ${ }^{110}$ die Frage, woher Eva, die später Geschaffene, von dem Verbot Gottes wissen konnte, führt dazu, Vorwürfe des Publikums hinsichtlich der Wahrheit des Erzählens zu fingieren; ${ }^{111}$ das schwierige Problem der visio Dei löst der Autor schließlich im Rückgriff auf die Tradition, um sich gleichzeitig selbst in deren Vermittlung zu verstricken. ${ }^{112}$ Viele Fragen bleiben offen, Antworten werden verweigert, auch wo sie problemlos scheinen. ${ }^{113}$ Was abseitig dünkt - wie Noah in kurzer Zeit die Tiere einfing (V. 1859ff.), wo die Taube bei ihrem

110 V. 822-832: het ich durchvarn den himel und die helle / und daz paradîse / und waer ouch alsô wîse / als der hêrre Salomôn was / und chunde swaz man ie gelas: / sô enmeht ich mit dem liste / iu daz minniste / wort nibt errechen wol, / wan ez ist wunders sô vol! / von diu sul wir mit mâzen / die rede enzît lâzen.

111 V. 1276: ir wonet gar, ich habe gelogen!

112 V. $2044 \mathrm{ff} . ;$ V. 2142-2155f.: Er hât eine tiefe rede getân, / ze diu, daz er uns benennet den man, / der dâ tichtete daz liet. / er entate sîn uürnamens niet, / er enwesse wol die wârheit: / der elliu rehtiu buoch dâ schreip, / mit dem wil erz behaben / . . / in genuogen steten hat sît / Gregôrius der von geredet.

113 S. etwa zunächst die Schilderung der Höllenfahrt nach geläufigen Motiven aus dem Descensus ad inferos (V. $3157 \mathrm{ff}$.) - und dann dennoch die Fragestellung, wo sich Christus in den drei Tagen vor der Auferstehung aufgehalten habe, gefolgt von einem Unsagbarkeitstopos, V. 3202f.: ich enchan noch enmac / iu der von nibt gezellen (s. Rupp [Anm. 34], S. 240); das markiert ein Bewußtsein von dem Konflikt zwischen erzählerischer Eigendynamik und theologisch-immanentem Sprachungenügen. 
dritten Ausflug nach Rückgang der Flut verblieb (V. 1943ff.) oder warum Maria überhaupt einen Ehemannn brauchte (V. $2463 \mathrm{ff} .:$ u.a. zur Täuschung des Teufels) -, erweist sich meist in der Tradition fundiert ${ }^{114}$ und wohl durch das 'naive' Interesse des Publikums an Leerstellen und lebensweltlicher Stimmigkeit der Bibelerzählung und der Heilsereignisse begründet. Personifikationen (Schöpfungsrat, Erlösungsbeschluß), fingierte Zwiegespräche dienen der Veranschaulichung, zeigen aber auch eine zunehmende Literarisierung, die begrifflich vom Autor des Anegenge noch kaum zu erfassen war.

Reflexionen der Literarizität heilsgeschichtlich-didaktischer Erzählung manifestieren sich auch dort, wo allegoretische Verfahren selbst zum Thema werden. ${ }^{115}$ Etwa in dem wohl um 1160 entstandenen Gedicht Vom Himmelreich, ${ }^{116}$ das wegen seiner hohen Form- und Sprachkunst ebenso von Bedeutung ist wie aufgrund seiner reich ausgemalten Alltagswelt. Der wahrscheinlich prämonstratensische Autor (aus dem Kloster Windberg bei Straubing) ${ }^{117}$ entwickelt hier in Anlehnung an Apk 4,3 eine Regenbogenallegorie, die er mit dem demütigen Bekenntnis des Unvermögens einleitet, sich an geistlicher Sinnhaftigkeit zu versuchen. ${ }^{118}$ Die Warnung vor theologischen Irrwegen in diesem Zusammenhang ist aus lateinischem Schrifttum vielfältig bekannt; ${ }^{119}$ und so beruft sich der Autor des Himmelreichs auf den eigenen Lehrer/Erzieher (magezoge, V. 139), um die Beschreibung und Deutung des Phänomens abzusichern. Von den vier furstlîchen Elementen, aus deren 'physikalischer' Zusammensetzung der Regenbogen entsteht, werden gemäß zeitgenössischer Auslegung Wasser und Feuer gedeutet hinsichtlich des Wunders der Gnade, des Gerichts und der prinzipiellen Erlösungsgewißheit des Menschen: als sowohl helflih unde heilsame wie egeslih unde freissame (V. 163f.), als Zeichen der Selektion der Guten wie der Vernichtung der Bösen (durch die Sintflut, das Höllenfeuer des Gerichts). Gleichzeitig kommt der Akt des Verstehens und der Auslegung selbst zur Sprache: in der Rede von bohe und tieffe des Sinnes (V. 155), von fünf leiblichen und fünf geistigen Sinnen (V. 149f.), aber auch im Hinweis auf die Bildlichkeit der

114 Teuber (Anm. 104); Rupp (Anm. 34), S. 217-260 (passim).

115 S. Hartmut Freytag, Die Theorie der allegorischen Schriftdeutung und die Allegorie in deutschen Texten besonders des 11. und 12. Jahrhunderts, Bibliotheca Germanica, 24 (1982), S. 43-50.

116 Handschrift München BSB, clm 9513: Gregor der Große, Moralia in Job, Bücher XI/XII; Eintragung des deutschen Textes auf $\mathrm{f} .1^{\mathrm{r}}-7^{\mathrm{r}}$ von der Hand des Schreibers des Windberger Psalters um 1174 (Hellgardt [Anm. 25], Nr. 153); Text im folgenden zitiert nach dem handschriftennäheren Abdruck Waag/Gernentz (Anm. 17), S. 202-220.

117 Literatur bei Wiebke Freytag, VL, IV, 2. Aufl. (1983), Sp. 18-21.

118 V. 129-134: Ih ne getar nah deme geiste erbalden me baz, / zerluogenne sîne suntergenge bin ih leider vile laz, /sûmich unde seine, geistlichiu dinch ersuochen, / jouh dere ih gwissiz urchunde vinde an den buochen. I sô ih furhte, daz mih gâhes ze dere unwârheite / min unvorbesehener sin ungvaerlîche verleite.

119 Reiches Belegmaterial bei H. Freytag (Anm. 115), S. 20 f., 46 (zur Stelle). 
Rede, ${ }^{120}$ die im folgenden primär anagogisch umgesetzt ist. Der Regenbogen im ganzen, etymologisch gedeutet als Friede (îris - îrin - [gr. eirene]; V. 121f., 184f.), ist Vorzeichen für zukünftige jenseitige Seligkeit, Paradigma für das Zusammenspiel von Verhüllung und vorblickender Enthüllung im Diesseits, ${ }^{121}$ damit zugleich Paradigma für die schließlich folgende Beschreibung des paradiesischen Daseins, eines geistlîchen Lebens (s. V. 255, 283), das sich nur kontrastierend, durch die Brechung gegenwärtiger Realität und Alltagswelt hindurch transparent machen läßt. ${ }^{122}$

Noch einen Schritt weiter in der reflexiven Durchdringung allegoretischer Deutungsmodelle geht etwa zur gleichen Zeit das hochinteressante, in der Millstätter Sammelhandschrift allerdings nur schlecht überlieferte Gedicht Die Hochzeit. ${ }^{123}$ Die Erzählung um einen chunich richen, deren Elemente später allegorisch interpretiert werden, beginnt selbst mit Bildhaftem, das dichterische Produktion, Sinnverhüllung und -enthüllung im Medium der Allegorie thematisiert. Angekündigt ist die Darbietung von einem heren spelle (V. 2) konkreter und zugleich zeichenhafter Art; und verglichen ist die Konstitution zeichenhaften Sinnes durch die Verdichtungsleistung des Autors mit dem schwierigen, erworbener Kenntnis bedürfenden Handwerk des Goldschmieds, der das geläuterte Feingold mit gröberem verbindet und durch Prägung oder Aufsatz (z.B. von Edelstein) das Schmuckstück formt. ${ }^{124}$ Das Bild springt von der Herstellung zur Anwendung: auf die Frauen, denen der kunstvolle Goldschmuck zur Zierde gereicht, die aber, wenn er ihnen in den Unrat fällt und sie ihn nicht wiederfinden, das schöne Stück verlorengeben und unwissentlich zur Tür hinaus kehren werden (V. 15-39). Ausdrücklich ist hier, bevor das Goldstück in weiterem heilsgeschichtlichen Zusammenhang interpretiert wird, auf die Analogie zu dem angekündigten heren spelle noch einmal hingewiesen. ${ }^{125}$ Was folgt, scheint traditionell: das Verständnis des Goldes als Weisheit, sapientia, ${ }^{126}$ das Wahre verborgen unter dem Häßlichen, Unbrauchbaren, Äußerlichen. Doch ist damit nicht auf den prinzipiellen Dualismus von Schein und Sein, von Oberfläche und Kern

120 V. $161 \mathrm{f} .:$ Wazzer unde fiur sint schînich an dem regenbogen, / dei ih bildiclîche in die rede hân gezogen.

121 V. 181f., 185-187: wande er dînen fride vore zeichinit den liuten, / daz wir chunnen gedenchen, waz iz sule bediuten, / daz in dîne holden umbe dînen stuol sebent (Apk 4, 4: die 24 Alten).

122 Bes. V. $304 \mathrm{ff}$. mit der Rede von den êren, die daz ouge vore werltlichen molten bie nih ne sibit.

${ }^{123}$ Handschrift (heute in Klagenfurt) um 1200 (Hellgardt [Anm. 25], Nr. 213); Text: Waag/Schröder (Anm. 17), II, 132-170.

124 V. 7-12: Swer diu zeichene wil began, / der sol guoten list haben, / also der smit vil guot / die wiere in daz golt tuot. / daz insigele er fur blat, / als erz gelernt hat.

125 V. 40-42: da mugent ir lernen liste, / swelhir so welle, / von einem heren spelle.

${ }^{126}$ S. Peter F. Ganz, "Die Hochzeit': fabula und significatio," Studien zur frühmbd. Lit. (Anm. 18), S. 58-73, hier S. 61. 
abgezielt, vielmehr auf den zwischen Unterdrückung oder Entfaltung des göttlich Angelegten, auf die christlich-immanente Realisation von Wahrheit: das Gold, die Weisheit muß zum Vorschein (schinen, V. 50) gebracht werden von denen, die von Gott mit Weisheit begabt sind und diese den weniger Privilegierten zu vermitteln haben. ${ }^{127}$ Das läßt sich auf die anfänglich skizzierte Rolle des Dichters als Vermittler und Deuter des von ihm selbst kunstvoll Hergestellten beziehen und damit ein erster Verständnishorizont abmessen, bevor im weiteren die Erzählung thematisch, als "Vorgang der Harmonisierung von Minne und Recht," 128 vorbereitet wird.

Daß die anfänglichen Verse der Hochzeit als poetologisches Programm gelesen werden können, ist verschiedentlich betont worden. ${ }^{129}$ Evident ist aber auch das komplexe Verhältnis der schillernden Bilder und Aussagen. Folgt man der Analogie zwischen Dichter und Goldschmied, so zeigt sich das Goldstück als Metapher für die Dichtung, sein Verlust als mögliche Mißachtung oder Verkennung des heren spelles. Das scheint zunächst auf das häufig thematisierte problematische Verhältnis zwischen (künstlerischer) Produktion und (eventuell mißlingender) Rezeption hinauszulaufen, erhält aber eine neue Wendung durch die folgende Ausdeutung des Bildes, die nicht nur über das zweifach metaphorisierte Goldstück Dichtung und Weisheit aufeinander bezieht, sondern eine neue Relation zwischen verborgener und offener sapientia einführt. Die verborgene Weisheit kann zwar die wahre sein, doch nur wenn sie zum Vorschein gebracht wird, während sie ansonsten verfällt, verrottet, heilsgeschichtlich nichtig wird. Das Bild vom Dichter als Goldschmied hat damit seine Gültigkeit verloren, anders als dieser darf er sein Werk nicht aus der Hand, damit dem möglichen Verlust anheimgeben: der Dichter ist Weiser, als Offenbarender und Erklärender nicht nur Produzent, sondern auch Vermittler mit Verantwortung für das Kommende. Das ungewöhnliche literarische Selbstbewußtsein des Prologes ist kaum zu verkennen: nicht um Inspiration und Sprachfähigkeit geht es, sondern um die rechte Handhabung des von Gott als ere (V. 59) Verliehenen. Thematisiert ist in der Allegorisierung des literarischen Aktes und der Explikation der Allegorie einerseits die Konstitution von Zeichenhaftigkeit im Sinnlichen, andererseits die Möglichkeit, die komplexe Signifikanz nicht untergehen zu lassen, sondern im Angesicht des Heilswerks zu entfalten.

Ungeklärt ist dabei noch die Rolle der Frau, die das Schmuckstück zwischen

\footnotetext{
127 Der Vorwurf gilt also dem, der den wistuom ... nieman seit unde ... nieman leret ... unde ez niht schinen lat (V. 43-50) - dazu der positive Gegenentwurf, V. 59-64: Swen got so geeret, / daz er in den wistuom geleret, / der schol in den zeigen, / die sin niweht eigen, / oder er nimt es ubir sich / vil starchen gerich.

${ }^{128}$ Ernst Hellgardt, "Zur Poetik frühmittelhochdeutscher Dichtung," Geistliche Denkformen (Anm. 30), S. 131-138, hier S. 137.
}

${ }_{129}$ Ganz (Anm. 126), S. 59-62 und besonders Hellgardt (Anm. 128), S. 136-138. 
den Unrat fallen läßt und schließlich verloren geben muß. Sie erscheint als Mittlerin zwischen der Allegorie und ihrer Explikation, assoziiert mit dem Gleichnis der verlorenen Drachme ( $\operatorname{lk} 15,8-10)$, das aber im Ansatz steckenbleibt: nicht um den Wert des einen verlorenen Stückes geht es zunächst, aber auch nicht um schuldhaftes Fallenlassen des Schmucks, denn das schließliche Vor-die-Tür-Kehren zeigt sich sogar parallel zum Akt der Verurteilung des 'falschen Weisen' durch das Gotteswort. ${ }^{30}$ Die strukturell motivierte Leerstelle evoziert Erwartungen, die erst in der Geschichte selbst eingelöst werden, wenn das Mädchen aus dem tiefen tal (V. 194), ein Goldstück undir der diete (V. 196), ihren Gemahl vom Gebirge empfängt, mit einer guldinen wiere (V. 283) geschmückt. Das Signal der Zierde genügt, um die Beziehung zum Prolog herzustellen; daß das reine Mädchen allerdings ihren Goldschmuck fallen lassen könnte, ist jenseits des Möglichen und kann im Kontext keine Rolle spielen - ein weiterer Hinweis auf den eher literarisch als thematisch funktionalisierten $\mathrm{Ge}-$ gensatz von Gold und mist im Prolog. Die komplexe Vorgabe intendierte offensichtlich nicht, das Verhältnis zwischen Erzählung und Allegorie auf das zwischen Verborgenheit und Offenbarkeit hin eindeutig transparent zu machen; aber umgekehrt bleibt auch der zwischen weltlichen und geistlichen Mustern schillernden Brautwerbungserzählung ${ }^{131}$ ein Bedeutungsüberschuß durch die folgenden, scheinbar alles überwuchernden allegorischen Deutungen hindurch ${ }^{132}-$ allein deshalb schon, weil die beiden Auslegungsreihen auf Tod und Leben bzw. Maria und die Heilsgeschichte hin ${ }^{133}$ nicht in der einfachen Zuordnung aufgehen. Wie einerseits die Erzählung spätestens mit der Erwähnung der guldinen wiere, wenn nicht schon mit dem Hinweis zur Bezeichnungsfunktion der huote (V. 236ff.), auf allegorische Explikation hin geöffnet ist, so kann diese andererseits die Überdeterminiertheit der Narration nicht verdrängen. Die Hochzeit bietet damit nicht nur vielleicht eine "geistliche Kontrafaktur... zu weltlicher

130 V. 54-56: also wirt er geschert / von der himelischen porte / mit dem gotes worte.

${ }_{131}$ Der letzte Prologabschnitt weckt deutlich heldenepische Erwartungen (V. 135: wigant; V. 138: degene; V. 144: hertuome), dem Publikum dürften mündlich-volkssprachliche Brautwerbungsgeschichten jedenfalls eher vertraut gewesen sein denn die als geistesgeschichtliche Vorläufer relevanten Auslegungen der Parabel der königlichen Hochzeit (Mt 22,2-14) oder des Hohenlieds (s. Ganz [Anm. 126], S. 62). Kartschoke (Anm. 17), S. 380f. hat auf das interessante, aber ebenfalls isolierte lateinische Bibelgedicht des Eupolemius (vielleicht um 1300) verwiesen, wo ebenfalls "in allegorischer Verhüllung die Heilsgeschichte erzählt" wird.

${ }^{132}$ Später werden auch golt und wiere ausgedeutet, ohne Beziehung auf das Prologprogramm (als Korrektur einer falschen, nur äußerlichen minne des Schmuckstücks von seiten der Frau?), V. 696-670: Daz golt vil ziere / daz bezeichent die bihte also here. / diu wiere dar inne / diu bezeichent die waren minne, / die daz mennisch ze got hat.

${ }^{133}$ Strukturierung bei Hugo Kuhn, "Allegorie und Erzählstruktur," ders., Liebe und Gesellschaft, hrsg. Wolfgang Walliczek (1980), S. 106-117, hier S. 113-117. 
Heldendichtung," ${ }^{134}$ vielmehr eine Thematisierung des komplizierten Verhältnisses verschiedener literarischer Typen und Sinnangebote, weit entfernt von dem entweder polemisch ausgrenzenden oder versteckt integrierenden Umgang geistlicher Texte mit weltlichen Stoffen und Erzählformen. Vereinzelt in dem umfunktionalisierten Erzählmodell wie der komplexen poetologischen Reflexion, ist sie doch Element einer Entwicklung zur stärkeren Durchlässigkeit geistlicher und weltlicher Texte, zur anwachsenden 'Literarizität' geistlichen Erzählens.

Das zeigt reflexhaft auch ein Text, der, in Aussagen und Formulierungen der Hochzeit oft nahestehend, noch gänzlich in die Paränese, in die Vermittlung christlich-kultischen Basiswissens eingebunden ist: die Deutung der Meßgebräuche. ${ }^{135}$ Die thematisch problemlosen Allegorien werden eingeleitet von zwei Gleichnissen: der Rede von einem vogelare, einem Vogelsteller, der mit chloben und harinen snuoren $\left(1,6 \mathrm{f}\right.$.) Beute macht, als Bild des Teufels; ${ }^{136}$ und der bekannten Weisheit, daß man Perlen nicht vor Säue werfen solle $(2,2) .{ }^{137}$ Beide stehen im Kontext der Situierung und Positionsbestimmung der kommenden Ausführungen; während der Vogelsteller auf die Gefahr falscher Versprechung, auf Verführung von der rechten warheit $(1,3)$ weg verweist, sind mit den swin die bekannten Spötter aufs Korn genommen, die die göttlichen Worte verachten und fallen werden $(2,5 \mathrm{ff}$.) - beide Seiten also, Produzenten wie Rezipienten, haben einander kritisch zu prüfen. Traditionell wie die biblischen Bilder und die folgende Bitte um Geistinspiration und Weisheit, damit Erzähler und Publikum den rechten Weg finden (Str. 3), ist die Allegorese der Meßgebräuche selbst; daß aber das Thema falschen Erzählens und Aufnehmens im weiteren Text keine Rolle spielt, verweist auf eine Verselbständigung von Legitimations- und Abgrenzungsstrategien, die fortgeschrittene volkssprachliche Hörererwartungen und sich ausbildendes literarisches Bewußtsein voraussetzt. ${ }^{138}$

Auch die immer wieder auftauchende Frage nach den Möglichkeiten der Sprache angesichts der Heilsereignisse wird nun gegen Jahrhundertende explizit

\footnotetext{
134 Ganz (Anm. 126), S. 71.

135 Úberliefert im Kontext der deutschsprachigen Predigtsammlung Speculum ecclesiae (München BSB, cgm 34, f. 132v-142r ; Handschrift aus dem 3. Drittel des 12. Jh.s, Hellgardt [Anm. 25], Nr. 146); Text: Maurer (Anm. 17), II, 290-315. Zum Text Gerd Mellbourn, Studia Neophilologica, 18 (1945/46), hier 53f. (Beziehung zur Hochzeit und zu dem Gedicht Vom Rechte); Edgar Papp, VL, II, 2. Aufl. (1980), Sp. 74-76.

$136 \mathrm{~S}$. vor allem Jr 5, 26: "inventi sunt at in populo meo impii / insidiantes quasi aucupes / laqueos ponentes et pedicas ad capiendos viros."

137 Mt 7,6: "Nolite dare sanctum canibus / neque mittatis margaritas vestras ante porcos."

138 Vgl. etwa auch die Fülle von Publikumsanreden in dem Fragment vom Leben Christi (Anm. 65).
} 
reflektiert. Der Autor eines deutschen Pilatus-Gedichts, ${ }^{139}$ vielleicht Herbort von Fritzlar, ${ }^{140}$ setzt in seinem Prolog mit dem Problem der deutschen Sprache und der eigenen Sprachbeherrschung ein, liefert, worauf Walter Haug aufmerksam gemacht hat, ein "einzigartiges literaturtheoretisches Dokument." ${ }_{141}$ Die deutsche Sprache sei unbetwungen, widerständig gegenüber literarischer Formung, könne aber doch fügsam gemacht werden wie der Stahl. ${ }^{142}$ Das klingt an Otfrids Sprachkritik an, ${ }^{143}$ doch geht es nun und in diesem Kontext nicht mehr um eine Beschreibung der Differenz zwischen dem Lateinischen und der zu etablierenden Volkssprache, sondern um die Umsetzung auf die Erzählung, auf die Situation des Sprechers:

$$
\begin{aligned}
& \text { swî ichz getouge, } \\
& \text { ich wil spannin mînen sin } \\
& \text { zô einer rede, an der ich bin } \\
& \text { ane gedenet vil cranc. } \\
& \text { mac sih enthalden mîn gedanc, } \\
& \text { unz ich sî geenden, } \\
& \text { sô weiz ih daz genenden } \\
& \text { mê tût dan mâze } \\
& \text { an sulben anlâze. } \quad \text { (V. 10-18) }
\end{aligned}
$$

Nicht allein die Sprache hat sich zu fügen, sondern vor allem der Sprecher, der der Kraft des Zusammenfügens und -haltens, des Mutes mehr als der mâze bedarf. Kein understatement also, vielmehr Bekenntnis zum Wagnis dichterischer Unternehmung, gestützt auf den poetischen $\sin$ als Medium und Instrument. Das wird im folgenden präzisiert:

$$
\begin{aligned}
& \text { Ih grîfen an den vollemunt } \\
& \text { unde sterke mînen funt } \\
& \text { mit dem êrsten sinne, } \\
& \text { der under unde inne }
\end{aligned}
$$

\footnotetext{
${ }^{139}$ Karl Weinhold, "Zu dem deutschen 'Pilatusgedicht': Text, Sprache und Heimat," ZfdPh, 8 (1877), 253-288, Text: 272-288. Uberlieferung nur in der verbrannten Straßburg-Molsheimer Handschrift (bald nach 1187, spätestens Anfang des 13. Jh.s; Hellgardt [Anm. 25], Nr. 156). Zur Quelle des deutschen Textes und zu verschiedenen Fassungen Joachim Knape, VL, VII, 2. Aufl. (1989), Sp. 669-682.

140 Zuletzt im Gefolge Edward Schröders eher befürwortend Joachim Knape, "War Herbort von Fritzlar der Verfasser des 'Verspilatus'? Zu den kontroversen Standpunkten Edward Schröders und Friedrich Neumanns," ZfdA, 115 (1986), 181-206.

${ }^{141}$ Haug (Anm. 6), S. 70-72, hier S. 72.

${ }^{142}$ V. 1-6: Man sagit von dûtscher zungen, / siu sî unbetwungen, ze vôgene herte. / swer si dicke berte, / si wurde wol zêhe, / als dem stâle ir geschêhe.

${ }^{143}$ Otfrid, Evangelienbuch, hrsg. Oskar Erdmann, 5. Auflage besorgt von Ludwig Wolff, ATB, 49 (1965), S. 4-7: Widmung an Erzbischof Liutbert; Weinhold (Anm. 139), S. 256; Haug (Anm. 6), S. 70 (zu Otfrid Kap. II).
} 


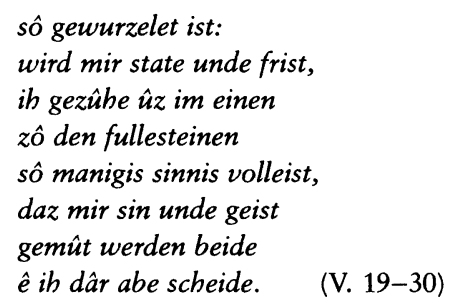

Der sin, der die rede ermöglicht, ist selbst gegründet auf einen vorgängigen und ursprünglichen sin als Wesen und Fundament alles Späteren, das nur Realisierung und Vollendung des Vorgegebenen darstellt. Doch dieser erste Sinn, Ursprung und Ziel zugleich, ist nicht zugänglich, ist Basis, obgleich dem Dichter entzogen, ist Gabe Gottes, des allumfassenden Schöpfers. Damit ist das traditionelle Verständnis des menschlichen Sinnes als göttlicher Geistesgabe, als Inspiration (nicht als ingenium) aktualisiert ${ }^{144}$ und wieder sicheres Territorium betreten: die Bitte um Unterstützung durch den Heiligen Geist und die Jungfrau wird ausführlich folgen. Nicht zu verkennen bleibt allerdings die ungewöhnliche, dann erst in Wolframs Willehalm-Prolog ähnlich akzentuierte Eigenständigkeit, die dem poetisch-menschlichen Sinn zugebilligt wird: das zeigt schon die Abfolge des Prologes, der im Konkreten und Sinnlichen ansetzt, bei dem Problem der sprachlichen Formung und des dazu nötigen menschlichen Vermögens, und erst sukzessive auf den ontologischen Ursprung hinführt; und das zeigt auch das Insistieren auf menschlichen Möglichkeiten ungeachtet des göttlichen Wirkungsaktes, das nicht zurückgenommene Insistieren auf der Sprachproblematik. Dieser erste Sinn, heißt es nun,

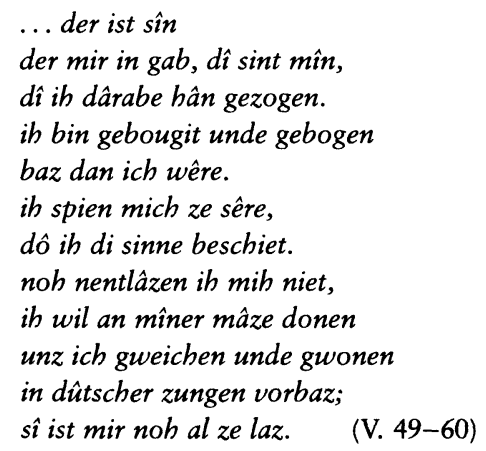

Die an das anfängliche Bild des zu formenden Stahls anschließende nun konstatierte größere Fügsamkeit mag sich, sollte Herbort der Autor des Pilatus

144 S. Friedrich Ohly, "Wolframs Gebet an den Heiligen Geist im Eingang des 'Willehalm," ZfdA, 91 (1961/62), 1-37; wieder (mit Nachtrag 1965) in: Wolfram von Eschenbach, hrsg. Heinz Rupp, Wege der Forschung, 57 (1966), S. 455-518, hier S. 483 ff., 516. 
sein, auf den eventuell früheren Trojaroman beziehen, ${ }^{145}$ sinnvoller sind die Verse wohl noch im Kontext. Besser gebougit unde gebogen ist der Sprecher, weil er die Fundamente für seine eigenen Möglichkeiten sprachlich-literarischer Leistung dargelegt, den Spielraum abgesteckt hat, in dem die menschlich-dichterische Arbeit an der Sprache stattfinden kann. Die Gefahr sich zu übernehmen, die Gefahr des Abweges (âwegic gên, V. 81) ist damit und mit der traditionellen Sprechhaltung des zweiten Prologteils gebannt, das Weitere verbleibt der praktischen Umsetzung, einer nicht schlecht gemeisterten, wie es scheint; ${ }^{146}$ der fragmentarische Erhaltungszustand verwehrt den Einblick in ein vielleicht späteres oder abschließendes Aufgreifen der Prologthematik. Was jedenfalls dort "bis zur Manieriertheit elaboriert" scheint, ${ }^{147}$ zeugt von einer Auseinandersetzung mit 'Literarizität' im Medium des geistlichen Textes auf bereits hohem Niveau. Daß die Erzählung des durchaus Unheiligen, an dem gleichwohl göttliches Wirken evident wird, für solche Reflexion größeren Spielraum bot, daß größere Freiheit des Stoffes von der des Gedankens kaum zu trennen ist, läßt sich annehmen, wenn auch nicht sichern: vergleichbare Geschichten sündiger Heiliger sind aus diesem Zeitraum meist nur bruchstückhaft erhalten; Hartmanns Armer Heinrich, der den Zusammenhang von Sünde und Heil expliziert, steht bereits außerhalb der literarischen Reihe, die dezidiert geistliche Normen in der Volkssprache vermittelte.

III.

Die skizzierten Differenzierungsleistungen im Anegenge, in der Hochzeit und dem Pilatus-Gedicht fallen bereits in eine Zeit der zunehmenden Etablierung nicht genuin heilsgeschichtlicher Erzählstoffe etwa seit der Mitte des 12. Jahrhunderts, markiert vor allem durch die Übernahme des Antikenromans aus dem Französischen. Die Anknüpfung an geistliche Erzählparadigmen bleibt dabei zunächst gewahrt: Alexander ist biblisch bezeugt, Eneas wird von Heinrich von Veldeke immerhin mittelbar mit der Heilsgeschichte in Verbindung gebracht. Aber auch in nun langsam schriftlich greifbar werdenden 'Spielmannsepen' deuten sich 'geistliche Umformulierungen profaner Typen' ${ }^{148}-$ bis hin zum Aufgehen im Legendarischen. Während hier der geistliche Erzählhintergrund zum Anschluß an bekannte Sinnparadigmen genügt und nur mäßiger Bedarf an reflexiver Aufladung der einfachen Erzählstrukturen besteht, erwachsen im Aufgreifen von chansons de geste, Antiken- und Artusroman stärkere Probleme aus

\footnotetext{
${ }^{145}$ Knape (Anm. 140), S. 202.

146 S. Weinhold (Anm. 139), S. 270 f.

${ }^{147}$ Kartschoke (Anm. 17), S. 342.

148 Haug (Anm. 6), Kap. IV.
} 
dem Konflikt zwischen der normativen Gültigkeit christlich-heilsgeschichtlicher Modelle und der Eigengesetzlichkeit der neuen Stoffe: die Auseinandersetzung mit der Wahrheit des Stoffes, der Plausibilität verschiedener Fassungen und der Wahrhaftigkeit des Erzählaktes gewinnt an Bedeutung. ${ }^{149}$

Auch Quellenberufungen grundsätzlich topischer Natur ${ }^{150}$ können so im Kontext signifikant sein. An Lambrechts Prolog zum Alexander wird - etwa zeitgleich mit der Kaiserchronik - auch das Nebeneinander von älteren und neueren Wendungen literarischer Begründung offensichtlich: der Hinweis an das Publikum, daß das Dargebotene in libro Machabeorum (V/S 12) zu finden sei, steht neben der Erwähnung des Alberîch von Bisinzo (V/S 13) als Autor der französischen Vorlage; und so ist es auch keineswegs mehr die Bibel, sondern dieser Alberich (de Besançon), ${ }^{151}$ der die Wahrheit der Geschichte bezeugt und damit Lambrecht die Möglichkeit gibt, sich von der Verantwortung zu suspendieren:

$$
\begin{aligned}
& \text { nîman enschulde sîn mich: } \\
& \text { louc er, sô liuge ich. } \quad(\mathrm{V} 17 \mathrm{f} .)^{152}
\end{aligned}
$$

Die Formulierung klingt zweifelsohne radikal. ${ }^{153}$ Alberich ist für Lambrecht Gewährsmann und Bürge, Garant der Wahrheit, und so kann das folgende Programm sich mit der Zitierung von Alberichs Intentionen begnügen, die sich ihrerseits auf Salomon stützen:

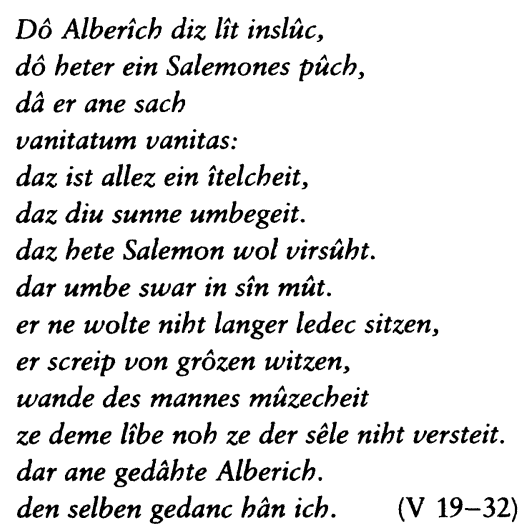

${ }^{149}$ Barbara Haupt, "Prinzipien literarischer Kulturvermittlung im Hochmittelalter," Archiv, 224 (1987), 1-13.

${ }^{150}$ Umfassende Sammlung bei Carl Lofmark, The Authority of the Source in Middle High German Narrative Poetry, Bithell Series of Dissertations, 5 (1981).

${ }_{151}$ Zuletzt gegen Pisançon und für Besançon Cola Minis, "Alberich von Bisenzun: 'Straßburger Alexander' V. 13 und Hs. 19," Amsterd. Beitr. zur älteren Germ., 23 (1985), 131-141.

152 Lamprecht, Alexander, hrsg. Karl Kinzel, Germanische Handbibliothek, 6 (1884).

${ }_{153}$ Abgeschwächt in der Straßburger Fassung: nieman ne schuldige mih: / alse daz bûch saget, sô sagen oub ih (S 17f.); s. Haug (Anm. 6), S. 86, Anm. 29. 
Dichtung als Mittel gegen Trübsinn und Müßigkeit ist ein bekannter Topos, ${ }^{154}$ und Lambrecht geht es ja auch um eine traditionelle Einsicht, die, legitimiert durch das lateinische Buch, von Alberich übernommen werden konnte. Allerdings nicht ohne Veränderung: indem er einerseits die Rolle der Antike (antiquitas) übergeht und das Gegeneinander zwischen Salomon und Alexander anders gewichtet, andererseits die Einsicht Salomons nun auf Alberich weitergibt und diesen zugleich aus dem Ruch der Schwäche (enfirmitas) befreit, ${ }^{155}$ entsteht eine ungebrochene Autoritätenkette, ist Lambrechts Unternehmen in jeder Weise abgesichert - stofflich durch das biblische Makkabäerbuch, in seiner literarischen Intention und Funktion durch das Vorbild Salomons, in der Wahrheit der geformten Bearbeitung durch Alberich. ${ }^{156}$

Entsprechend folgt Lambrecht auch Alberich, wenn es darum geht, die Wahrheit der Geschichte zu verteidigen, d.h. hier, am Beginn der Erzählung, die Abstammung Alexanders vom Einfluß des Zauberischen ${ }^{157}$ freizuhalten. Die gegenteiligen Meinungen werden - der Kaiserchronik vergleichbar - wieder als Produkte von Lügnern, als lugenmêre von lugenâren (S 83/89) abgetan, die kein ehrbarer Mensch je als Geschichten achten sollte:

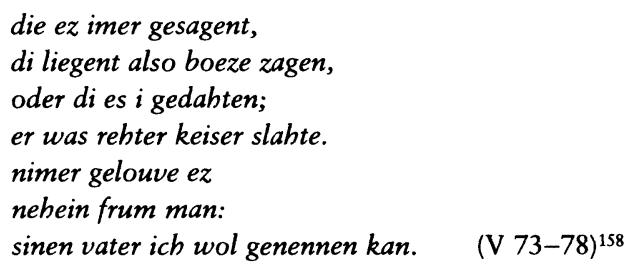

Das Schema der Polarisierung bleibt einfach, doch Wahrheit und Lüge sind nicht mehr von vornherein heilsgeschichtliche Kategorien, auch wenn das Habacht auf ihre Differenzierung dem frumen nahegelegt wird; sie beinhalten

154 Curtius (Anm. 9), S. 98f.; Haug (Anm. 6), S. 85.

155 Alexandre, V. 1-5: "Dit Salomon al primier pas, / quant de son libre mot lo clas, / 'est vanitatum vanitas / et universa vanitas.' / poyst l'oume fayni' enfirmitas, / toylle s'en otiositas, / solaz nos faz' antiquitas, / que tot non sie vanitas." Zum Prolog zusammenfassend Wolfgang Fischer, Die Alexanderliedkonzeption des Pfaffen Lambrecht, Medium Aevum, 2 (1964), S. 42-44, zu Lambrecht S. 45-49; Haug (Anm. 6), S. 84-88.

156 Zur Verschiebung des Gedankens in S auf Exemplarizität hin s. Fischer, S. 49.

157 Nicht Sohn Philipps, sondern des ägyptischen Magiers Nektanebus ist Alexander in den griechischen und lateinischen Fassungen wie auch im Basler Alexander: Alberich, Alexandre, V. 27-32: "Dicunt alquant estrobatour / quel reys fud fils d'encantatour, / mentent, fellon losengetour; mal en credreyz nec un de lour; / qu'anz fud de ling d'enperatour / et filz al rei Macedonor."

${ }^{158}$ S 89-91: sulbe lugen mêre / sulen sîn ummêre / iegelîchen frumen man. 
keine Dichotomisierung von geistlicher und weltlicher Literatur oder von autoritativer Schriftlichkeit und scophelîcher Mündlichkeit, ${ }^{159}$ sind weit eher schon historisch faßbar. Wenn sich an Alexander Weltgeschichte entfalten sollte, wie Annolied und Kaiserchronik demonstriert hatten, ${ }^{160}$ mußte er keiser slabte/kunincslabte (V 76/S 88) sein; der Gang des Gottesreiches aber kann an ihm nur ex negativo erfahren werden - was Lambrecht durch die Einfügung der kontrastierenden Parallele zu Salomon, dem Repräsentanten des Gottesreiches, verdeutlicht (S 65-82). ${ }^{161}$ Die (heils)geschichtliche Position, die die Vorauer Handschrift durch die Einordnung des Alexander zwischen alt- und neutestamentliche Stoffe, zwischen Jüngere Judith und Avas Leben Jesu markiert, hat die Straßburger Fassung verdeutlicht: an Alexander wird nun das Problem falschen und richtigen Herrscherverhaltens beleuchtet, ${ }^{162}$ der Übergang zwischen dem zweiten und dritten, dem persischen und mazedonischen Weltreich konkretisiert. ${ }^{163}$

Während der phaffe Lambrecht im Prolog nur mittelbar die Autorität des biblischen Buches und das vanitas-Diktum des biblischen Gewährsmanns Salomon zur Fundierung des eigenen Unternehmens heranzieht, stellt der phaffe Konrad (um 1172) sein Aufgreifen der französischen Reichsgeschichte ganz in die Perspektive der frühmittelhochdeutschen geistlichen Literatur; nur die Konzentration der Elemente - Gott als Schöpfer, Inspirationsbitte, Wahrheit/Lüge, Themenangabe - auf wenige Verse (V. 1-11) deutet vielleicht an, daß hier nicht nur christliche Weisheit zu vermitteln, sondern ein Typus geistlich orientierter Rede aufzurufen war. Der Epilog knüpft daran an, wenn er nun auch für Herzog Heinrich (den Löwen) den Lohn Gottes wünscht (V. 9017-19), und überschreitet zugleich das Werk im Hinblick auf die göttliche Transzendenz, aber auch auf Reichsgeschichte und Mäzenatentum. Der Stoff ist zwar (ästhetisch) wertvoll, so Konrad, doch suoz wurde er erst durch Heinrich und seine Frau, erst durch die Realisierung ihres Auftrags wurde Heilsgeschichte ins litera-

159 An späterer Stelle wird Lambrecht bekanntlich zur Beschreibung von Alexanders Schlacht gegen die Perser am Granicus Figuren aus Heldensage und Trojageschichte gleichermaßen heranziehen (V 1321-38, S 1830-48); s. Cola Minis, "Über die Hildestelle in Lambrechts 'Alexander,” Amsterd. Beitr. zur älteren Germ., 12 (1977), 47-70.

160 Annolied (Bulst [Anm. 44]), V. 207-236; Kaiserchronik (Schröder [Anm. 49]), V. 536-564.

161 Vgl. Helmut de Boor, Die deutsche Literatur von Karl dem Großen bis zum Beginn der höfischen Dichtung 770-1170, Geschichte der deutschen Literatur, Bd. I, 3. Aufl. (1957), S. 237.

162 Peter K. Stein, "Ein Weltherrscher als vanitas-Exempel in imperial-ideologisch orientierter Zeit?" Stauferzeit: Geschichte - Literatur - Kunst, hrsg. Rüdiger Krohn u.a. (1978), S. 144-180.

${ }^{163}$ S. Peter Strohschneider und Herfried Vögel, "Flußübergänge: Zur Konzeption des 'Straßburger Alexander,” ZfdA, 118 (1989), 85-108. 
rische Werk umgesetzt. ${ }^{164}$ Die göttliche Erwähltheit der beiden adelt - vermittelt über die Fiktion eines karolingischen Originalwerks, eines authentischen buoches - auch Konrads Werk:

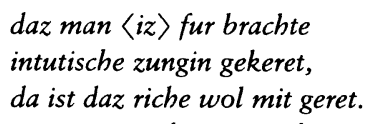

Es folgt eine Stilisierung Heinrichs als davidsgleichem, königsgleichem Herrscher, ein Preis seiner Tugenden und Vorzüge (V. 9039ff.). ${ }^{165}$ Daß die doppelte Parallelisierung Heinrichs mit dem biblischen Idealherrscher David (in der Chanson de Roland: Salomon) und dem christlichen Idealherrscher Karl eine reichspolitische Aussage intendierte, ist evident; Konrad formuliert sie nicht explizit, macht aber deutlich, daß in der Person Heinrichs christliche Herrscherfähigkeit auch ohne das Königsamt verwirklicht sein konnte. Noch einmal kehrt der Blick nach der Huldigung auf das Werk zurück - in überraschender Wendung:

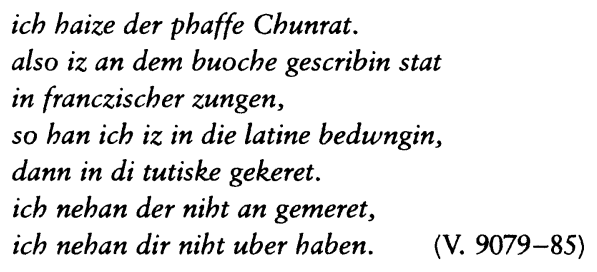

Dem reichsgeschichtlichen Aspekt, der die erste Erwähnung der Übertragungsleistung (keren, V. 9033) leitete, ist nun ein persönlicher zur Seite gestellt. Weder eine Nobilitierung des Werks durch eine fingierte lateinische Autorität ist hier wohl angestrebt noch die tatsächliche Existenzbezeugung einer vollständig ausgeformten lateinischen 'Rolandias.' Es sollte eher - folgt man der umsichtigen Deutung Dieter Kartschokes - der mühsame Charakter einer Umsetzung französischer Epik ins Deutsche zum Ausdruck gebracht werden. ${ }^{166}$ Das Problem liegt in der Ausgangssprache, die bedwungin werden muß, um dann in einem zweiten einfacheren Schritt - über eine vielleicht skizzenhafte lateinische Konzeption - ins Deutsche gekert, dort zugänglich gemacht werden zu können. Konrads ausdrücklicher Hinweis spiegelt ein in der Tat bedeutendes Problem im

${ }^{164}$ Pfaffe Konrad, Rolandslied, hrsg. Carl Wesle, 3. Aufl. besorgt von Peter Wapnewski, ATB, 69 (1985), V. 9020-25: di matteria di ist scone. / di suoze wir uon im haben: / daz buoch hiz er uor tragen, / gescriben ze den Karlingen. / des gerte di edele herzoginne, / aines richen chuoniges barn.

${ }^{165}$ S. zum folgenden Vollmann-Profe (Anm. 17), S. $135 \mathrm{f}$.

166 Dieter Kartschoke, "in die latine bedwungin: Kommunikationsprobleme im Mittelalter und die Ubersetzung der 'Chanson de Roland' durch den Pfaffen Konrad,” PBB, 111, No. 2 (1989) [Festgabe für Joachim Bumke], 196-209. 
Umgang mit französischem Zehnsilber und Laissenstil, ein Problem, das Wolfram dann im Willehalm erst mit hoher stilistischer und erzählerischer Freiheit bewältigen wird. ${ }^{167}$ Der Hinweis auf die wahrhaftige und getreue Transponierung hat vor diesem Hintergrund nicht einfach topischen Charakter, leuchtet vielmehr gerade angesichts des Eingeständnisses der sprachlichen Schwierigkeiten ein; und auch die Bitte um Gedenken und gläubige Fürsprache des Publikums hat konkreteren Beiklang als gewöhnlich, wenn man berücksichtigt, "daß die literarische Übertragung und Nachdichtung eines französischen Gedichts zumal im Osten des Reichs noch so unerhört neu war und eine derart ungewohnte Anstrengung erforderte, daß ihrer hinsichtlich der Verdienstlichkeit solcher Unternehmung zurecht gedacht werden konnte." 168

Von den Problemen der Etablierung eines neuen Stoffbereiches, einer neuen Erzählwelt ist in Konrads Rolandslied nur ein Reflex greifbar, in sprachlicher Hinsicht. Weitergehende Auseinandersetzung mit dem noch (und auch später zumeist) ungewohnten Typus der chansons de geste mochte sich durch die christliche Anreicherung und den stärkeren Akzent auf der Person Karls ${ }^{169}$ erübrigt haben - die schwierige stoffliche und sprachliche Integrationsleistung des poetologisch vielleicht noch wenig sensibilisierten Autors zog hier die mögliche Reflexion an sich.

Doch auch der fast zeitgleiche Eneasroman Heinrichs von Veldeke (1174/83) bietet, ungeachtet neuer episch-deskriptiver Entfaltung, kaum explizite literarische Positionsbestimmungen. Der Text setzt wie seine altfranzösische Vorlage ohne Prolog ein, medias in res, nur mit einer Einstimmungsformel an die Adresse des Publikums versehen (s. Anm. 46). Man muß in der Unmittelbarkeit des Beginns keinen Gattungshinweis auf heldenepischen Charakter des Textes sehen, ${ }^{170}$ darf aber wohl überrascht sein, daß Heinrich sein umfangreiches Erzählprojekt ohne Positions- und Funktionsbestimmungen hinausgehen ließ. Manches wird im Laufe des Werks nachgeholt: die Untermauerung der Autorität durch häufige Berufung auf die bûch und Betonung der Wahrheit des Gebotenen. ${ }^{171}$ Doch der ansonsten breit ausgespielten Erzählerrolle fällt keine Thematisierung des literarischen Werks als solchem zu, erst der Epilog setzt hier Akzente: zunächst mit der zwar wohl authentischen, aber vielleicht nicht von

167 Vgl. (ohne Bezugnahme auf das Rolandslied) Antje Mißfeldt, Die Abschnittsgliederung und ihre Funktion in mittelhochdeutscher Epik: Erzähltechnische Untersuchungen ... unter Einbeziehung französischer Laissentechnik, Göppinger Arbeiten zur Germanistik, 236 (1978).

168 Kartschoke (Anm. 166), S. 209.

169 S. Friedrich Ohly, "Die Legende von Karl und Roland," Studien zur frühmbd. Lit. (Anm. 18), S. 292-343, hier S. 314f.

170 S. Kartschoke, Kommentar (Anm. 46), S. 760 f.

${ }^{171}$ Etwa V. 5100f./5116f.: daz welnt die wîsen vor wâr, / die ez von den bûchen sagent. / ... / nû wizzen wir daz wol vor wâr, / die wir diu bûch hân gelesen, / daz daz niht ne mach wesen. 
Veldeke stammenden Schilderung von Manuskriptdiebstahl und -fertigstellung, die ein ungewöhnlich klares Licht auf adliges Literaturinteresse wirft, ${ }^{172}$ dann in Wahrheitsbeteuerungen und Konkretisierungen der Quellenlage. Heinrich nennt nun welsche bûch als Vorlage und Vergil als geistigen Vater, reiht zudem Betonungen seiner erzählerischen Wahrhaftigkeit aneinander. Wichtig ist ihm, daß schon die französische Vorlage im Rückgang auf die lateinische Aeneis deren Wahrheit nicht angetastet hat, daß eine ungebrochene Tradition historischer Glaubwürdigkeit besteht, die es ermöglicht, - ähnlich wie bei Lambrecht - die inhaltliche Verantwortung den Quellen zuzuschieben, sich selbst nur mit der des zu Werktreue verpflichteten 'Übersetzers' zu belasten:

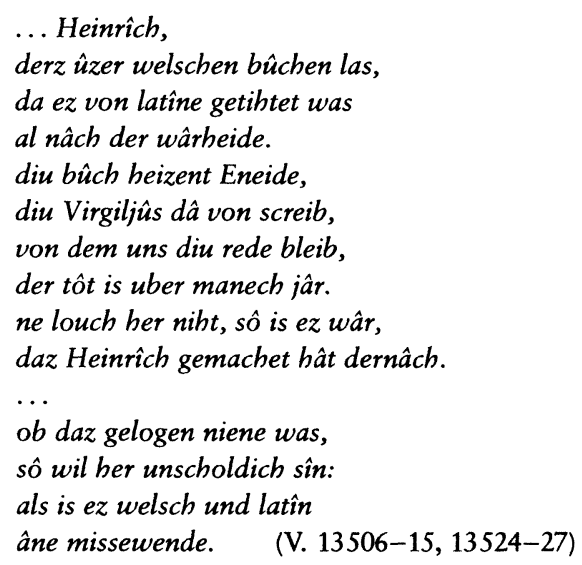

Die Darbietung des Eneasstoffes konnte, wie es scheint, in ihrer Historizität und Authentizität zumindest in den Augen Heinrichs von Veldeke für sich selbst stehen $^{173}$ - in stärkerem Maße noch als die heilsgeschichtliche Legitimation des Rolandsliedes in den Augen Konrads.

Direkt anschließen läßt sich noch ein Blick auf einen Text, der, ebenfalls unter dem Patronat Hermanns von Thüringen entstanden, ${ }^{174}$ wohl eine Vorgeschichte zu Heinrichs Eneasroman liefern sollte: das liet von Troye des aus Hessen

172 Kartschoke, Kommentar (Anm. 46), S. 824f., 848f. Als Interessenten sind genannt: die Gräfin Margarete von Kleve, Heinrich (Raspe III.), Hermann von Thüringen und sein Bruder Friedrich (V. 13429-90); Joachim Bumke, Mäzene im MA (1979), S. $113 \mathrm{ff}$.

${ }^{173}$ Die positive Rezeption, die in der 'Manuskriptgeschichte' zweimal erwähnt ist (V. 13434: daz is gnûgen wizzenlîch, / daz herz tibten kunde; V. 13478f.: want diu rede dûhte in [Hermann] gût / und daz getibte meisterlîch), bestätigt, auch wenn diese nicht von Heinrich selbst stammen sollte, diese Tendenz.

${ }_{174}$ Zur Rolle des als Vermittler genannten Grafen von Leiningen (wahrscheinlich Friedrich I.) s. jetzt Uwe Meves, “Der 'graue von Liningen' als Vermittler der französischen Vorlage des 'Troja-Romans' Herborts von Fritzlar," Akten des VIII. Kongresses der IVG, hrsg. Eijiro Iwasaki und Yoshinori Schichiji, Bd. VI: Rezeption (1991). 
kommenden gelarten schuolere Herbort von Fritzlar. ${ }^{175}$ Herbort bezeugt im Prolog - wie Heinrich von Veldeke im Epilog - seine Gewährsleute (V. 47-59): als Vorlage ein Buch franzoys und walsch (der Trojaroman Benoîts de SainteMore), das seinerseits auf der griechischen Fassung des Augenzeugen Dares (Phrygius) und der lateinischen Übersetzung des Cornelius (Nepos) beruhe. Über die Wahrheit der Erzählung verliert Herbort nicht viele Worte: Sin fuge ist gantz und ane falsch (V. 48) sagt er von der Vorlage, und seine eigene Rolle im Prozeß der Tradierung ist, der Posteriorität bewußt, als die des vierten oder fünften Rades beschrieben (V. 74-83). Von der Wahrhaftigkeit der eigenen Umsetzung spricht Herbort kaum; das ist plausibel nicht nur, weil er im weiteren verschiedentlich seine Quelle berichtigen wird, sondern auch weil er bereits in einem ersten Prologteil generelle Bedingungen des Dichtens ausführlich dargelegt hat. Künstlerische Meisterschaft wird dort nicht wenig selbstsicher, mit "unverhohlenem Kunstbewußtsein," 176 beschrieben in Termini von abbreviatio und dilatatio, ${ }^{17}$ doch ebenso die Notwendigkeit der Zurückhaltung hervorgehoben, um Ungelehrte nicht auf den falschen Weg zu führen:

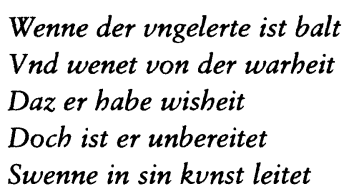

Die Metaphorik des Weges, das Bild des Blinden und Sehenden veranschaulichen das angeschlagene Thema: Verantwortung des Wissenden, der die Differenz zwischen Wahrheit und Weisheit kennt, für die Unwissenden - eine klare Positionsverteilung, die im folgenden immerhin relativiert wird durch eine $\mathrm{Zu}$ rücknahme des Autors, der sich selbst noch als ivngere (V. 30) und Lernenden einzustufen hat. So wird das Dichten für ihn eine Verbindung von Lehren und Lernen sein; wird der eigene poetische sin erst langsam durch ausdauernden Fleiß und stete Bemühung einer nur 'tröpfelnden' Inspiration geschmeidig, biegsam genug werden, um der Erzählintention zu genügen. ${ }^{178}$ Die Nähe zum Pila-

${ }^{175}$ Herbort von Fritzlâr, liet von Troye, hrsg. Karl Frommann, Bibliothek der gesammten deutschen Nationalliteratur, 5 (1837) [über der Zeile stehende n- und d-Kürzel sind im folgenden aufgelöst]. Die Datierung des Werkes schwankt zwischen um 1190 und um 1210; das frühere Datum wird in der letzten Zeit meist favorisiert. Ausführlichere Interpretation des Texts zuletzt bei Helga Lengenfelder, Das 'Liet von Troyge' Herborts von Fritzlar, Europäische Hochschulschriften, I, 133 (1975).

176 Knape (Anm. 140), S. 201.

17 V. 4-6: Minren und meren / Witen und engen / Kurtzen und lengen.

178 V. 38-41: Also ban ich selden ganzen regen / Ez muz mir einzeln tropfen in / Daz mir weichen sol den sin / Von flizze wirt der man gelart; V. 88-91: Vnd baniche minen sin dar ane / Daz ich in bekere deste baz / Wen der ist herte und laz / Ich wil in bigen ob ich kan. 
tus-Prolog ist unübersehbar, ${ }^{179}$ doch ebenso das Fehlen jeder transzendenten Begründung des dichterischen Vermögens: der sin, angesichts der drei Ursprungssprachen der Troja-Geschichte als notwendig dreifach präzisiert (V. $63 \mathrm{ff}$.), soll rehte geleite (V. 69) sein, wird weitgehend autonomes 'Organ' der erzählerischen Vermittlung. Herbort, obwohl der eigenen späten Position inne, kann sich so doch als Weiterführer oder Vollender begreifen, ohne den Nutzen seiner Erzählung lange inhaltlich zu begründen:

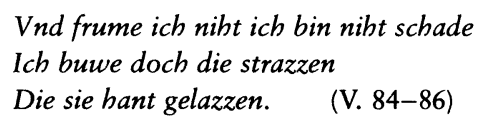

Hier wird deutlich, welchen Stand die Emanzipationsbemühungen volkssprachlicher literarischer Reflexion gegen Ende des 12. Jahrhunderts erreicht haben. Der Geschichtlichkeit von Literatur, die angesichts der Heilsvermittlung zuerst in den Blick kam, tritt nun die Literarizität erzählter Geschichte gegenüber, der medialen und instrumentellen Funktion der Literatur die Möglichkeit, Sinnhorizonte selbst zu setzen und zu entfalten. Die Preisgabe des Historischen an eine erzählimmanente fiktionale Sinnkonstitution wird der nächste, allerdings ungleich radikalere Schritt sein. Der Trojaroman steht schon vor dem Horizont des höfischen Romans, ${ }^{180}$ signalisiert den Weg zu freier Verfügbarkeit und Autonomie des literarischen Aktes, damit auch zu neuen, komplexeren Formen literarischer Theoriebildung. So läßt sich an dieser Stelle zurückblicken.

IV.

Die beschriebenen expliziten Reflexionsansätze repräsentieren, das darf nicht vergessen werden, nicht das gesamte Spektrum der deutschen Literatur bis zum Ende des 12. Jahrhunderts. Vieles ist nur fragmentarisch, und dann meist ohne Anfang und Ende, erhalten, anderes gehört zwar zum Bedeutenderen des deutschen Schrifttums, kommt aber fast ohne literarische Programmatik aus. Dazu zählen die alt- und neutestamentarischen Bearbeitungen (Genesis, Exodus, Vorauer Bücher Mosis, Ava), die heilsgeschichtlichen Basisunterweisungen der sog. Mittelfränkischen Reimbibel, des Armen Hartmann (Rede vom Glauben) und eines gewissen Heinrich (Litanei), aber auch die deutschen Hoheliedbearbeitun-

\footnotetext{
179 Knape (Anm. 140), S. 202.

${ }^{180}$ Schwer zu kalkulieren ist der Einfluß von Hartmanns unbekanntem Erec-Prolog, überhaupt der mit der Übernahme der matière de Bretagne anzusetzenden neuen Reihe; Überlegungen zum verlorenen Prolog bei Walter Haug, “der aventiure meine," Würzburger Prosastudien II: Untersuchungen zur Literatur und Sprache des Mittelalters [Kurt Ruh zum 60. Geburtstag], hrsg. Peter Kesting, Medium Aevum, 31 (1975), S. 93-111; wieder in Haug, Strukturen (Anm. 14), S. 447-463.
} 
gen (Williram von Ebersberg, St. Trudperter Hoheslied). Dazu zählen auch die stärker mit der Mündlichkeit verbundenen Texte aus Helden- und Brautwerbungsepik, deren Literarisierung gegen Ende des Jahrhunderts faßbar wird. Das macht die Signifikanzgrenzen des angedeuteten Differenzierungsprozesses in methodischer wie historischer Hinsicht deutlich. Was die Texte selbst angeht, ist zu berücksichtigen, daß oft schon der Selektionsakț, der einer literarischen Form oder textuellen Struktur zugrundeliegt, auf literarischer Auseinandersetzung beruht, daß also mit den dargestellten Passagen nicht selten nur die Spitze eines Eisbergs sondiert ist - zugleich liegt der Gewinn dieser Beschränkung darin, an der 'Wahrnehmungsdifferenz' zwischen Oberfläche und Untergrund, zwischen Formuliertem und Impliziertem festzuhalten. Was geschichtliche Verankerung, historische Stringenz und Plausibilität literarischer Theoriebildung angeht, zeichnet sich erneut das grundsätzliche Problem von Evolution und Synchronizität ab, das einstweilen sich mehr in Fragen als in Antworten fassen läßt.

Literarische Reflexion bildet sich in Bezug auf materielle Bedingungen einer den Lebensstandard langsam verbessernden Kultur, damit an vielfältige Faktoren, Institutionen, Träger einer allgemeinen Geschichte gebunden, und bildet sich in engem Zusammenhang mit Bedingungen der Edukation und Wissensvermittlung (hier vor allem mit einer langsam fußfassenden Schriftlichkeit), ${ }^{181}$ damit in unterschiedlichem Maße an lateinische Traditionen und pragmatische Intentionen gekoppelt. ${ }^{182}$ Sie scheint am ehesten dort notwendig, wo Unvertrautes und Unselbstverständliches zu legitimieren war, wo neue literarische Stoffe und Formen zu etablieren waren; scheint aber auch eine Eigendynamik (etwa bei Autornennungen) ${ }^{183}$ zu entwickeln, die auf traditionelle Formen zurückwirkt. Innerhalb des allgemeinen Prozesses der Differenzierung und Individualisierung, der Verfeinerung lebensweltlicher und literarischer Imagination nehmen die Ansätze der Theoriebildung also nur einen kaum homogenen Teilbereich ein, der auf weitere Inkongruenzen führt: während sich etwa das Rolandslied trotz der Behandlung eines neuen Stoffbereichs in seiner literarischpoetologischen Position noch ganz auf die Reihe frühmittelhochdeutscher geistlicher Texte bezogen zeigt, überschreitet die Hochzeit das volkssprachliche

\footnotetext{
${ }^{181}$ S. Walter Haug, "Schriftlichkeit und Reflexion: Zur Entstehung und Entwicklung eines deutschsprachigen Schrifttums im Mittelalter," Schrift und Gedächtnis: Beiträge zu einer Archäologie der literarischen Kommunikation I, hrsg. Aleida und Jan Assmann, Christof Hardmeier (1983), S. 141-157; wieder in Haug, Strukturen (Anm. 14), S. 51-66. Klaus Grubmüller, "Mündlichkeit, Schriftlichkeit und Unterricht: Zur Erforschung ihrer Interferenzen in der Literatur des Mittelalters," DU, 41, No. 1 (1989), 41-54.

${ }^{182}$ Zum Konzept der 'Interessenbildung' s. Joachim Heinzle, "Wie schreibt man eine Geschichte der deutschen Literatur des Mittelalters?” DU, 41, No. 1 (1989), 27-40 und Literarische Interessenbildung im Mittelalter: Symposion Maurach 1991, hrsg. Joachim Heinzle u.a., Germanistische Symposien.

183 Vgl. L. Peter Johnson, "Die Blütezeit und der neue Status der Literatur," Literarische Interessenbildung im Mittelalter.
} 
geistliche Reflexionsniveau erheblich, um zugleich dem heilsgeschichtlichen Paradigma thematisch verpflichtet zu bleiben, in der metrischen Formung sogar hinter dem zeitgenössischen Standard zurückzustehen.

Wieder ist man damit auf 'strukturierte Bündelungen' von Elementen verwiesen, auf verschiedene Diskurse und sich verflechtende Strukturen, different in Konstanz und Wandel, in Art und Dauer ('longues durées'). ${ }^{184}$ Unterschiedliche Entwicklungsniveaus und fehlende Relationen der Texte, aber auch schwer faßbare Verhältnisse von expliziter und impliziter Reflexion drohen das Phänomen literarischer Theoriebildung, das sich ohnehin erst langsam vom Konventionellen abhebt, von neuem zu einem Vexierbild zu machen, das weder ausreichende Konsistenz noch eindeutige Verbindung zu außerliterarischen Prozessen aufweist. Die Individualisierungstendenz des 12. Jahrhunderts ${ }^{185}$ ist nur ein allgemeiner Rahmen für Texte, deren Positionsbestimmung 'komplexere Evolutionsmodelle'186 und Beschreibungskategorien benötigt. Denn das Jahrhundert entfaltet immerhin auch ein komplexes Nebeneinander von 'aufklärerischen' und neuen mythischen Konzeptionen ${ }^{187}$ und offenbart eine verwirrende Fülle von experimenta medietatis, ${ }^{188}$ die moderne Strukturierungen von Geschichte immer neu durchdacht sein lassen wollen. Die Eigengesetzlichkeit von Sprachund Gattungsformen, von Bildungs- und Literarisierungsprozessen ist zu ermitteln, aber auch auf ihre Schnittpunkte mit anderen Serien zu befragen und mit formalen oder strukturellen Analogien zu korrelieren. ${ }^{189}$ So müßte der Blick auf Entwicklungen der altfranzösischen Literatur, ${ }^{190}$ auf Theorieimplikationen in

\footnotetext{
${ }^{184}$ Gründliche Auseinandersetzung mit der französischen Geschichts- und Literaturwissenschaft bei Sabine Jöckel, "Nouvelle histoire" und Literaturwissenschaft, Studienausgabe, Bd. I (1985); s. a. Haug (Anm. 14), S. $91 \mathrm{f}$.

${ }_{185}$ Vgl. unter vielem Charles H. Haskins, The Renaissance of the 12th Century (1927); Richard W. Southern, The Making of the Middle Ages (1952); dt.: Geistes- und Sozialgeschichte des Mittelalters: Das Abendland im 11. und 12. Jahrhundert, 2. Aufl. (1980); Colin Morris, The Discovery of the Individual 1050-1200, Nachdr. (1987). Zu allgemein in den als signifikant herangezogenen Kategorien bleibt trotz wichtiger Überlegungen Hans Bayer, "Zur Soziologie des mittelalterlichen Individualisierungsprozesses: Ein Beitrag zu einer wirklichkeitsbezogenen Geistesgeschichte," AKG, 58 (1976), 115-153.

${ }^{186}$ Jan-Dirk Müller, "Literaturgeschichte/Literaturgeschichtsschreibung", Erkenntnis der Literatur. Theorien, Konzepte, Methoden der Literaturwissenschaft, hrsg. Dietrich Harth und Peter Gebhardt (1982), S. 195-227, hier S. 199a.

187 Hans Fromm, “'Aufklärung' und neuer Mythos im Hohen Mittelalter,” Arbeiten zur deutschen Literatur des Mittelalters (1989), S. 1-23.

188 Walter Haug, "Experimenta medietatis im Mittelalter," Aufklärung und Gegenaufklärung in der europäischen Literatur, Philosophie und Politik von der Antike bis zur Gegenwart, hrsg. Jochen Schmidt (1989), S. 129-151.

189 S. etwa generell Göran Hermerén, Influence in Art and Literature (1975).

190 Stellensammlung: Französische Literarästhetik des 12. und 13. Jahrhunderts: Prologe - Exkurse - Epiloge, hrsg. Ulrich Mölk, Sammlung romanischer Ubungstexte, 54 (1969).
} 
lateinischer Chronistik, ${ }^{191}$ auf die Rolle der Selbsterkenntnis in philosophischer und theologischer Meditation ${ }^{192}$ oder Darstellungen des künstlerischen Aktes und Künstlersignaturen in Buchmalerei und Plastik ${ }^{193}$ zu jener 'allgemeinen Geschichte' (Foucault) hinführen, die kausaler Verknüpfungen entbehrt, sich vielmehr mittels Asynchronitäten und interner Verschiebungen bildet. Aber auch sie bedarf wenigstens einer Zahl von (vielleicht heterogenen) Regeln, die sich zu 'Diskursformationen' fügen, von Formelementen (Kubler), die sich von klar bestimmbaren Innovationen her als Transformationen beschreiben lassen. Damit stellt sich von neuem das Problem einer Verhältnisbestimmung von Konstanten und Variablen, von Konventions- und Innovationsfaktoren.

Die Reflexionsansätze der volkssprachlichen Texte des 11. und 12. Jahrhunderts vermitteln zwar oftmals erst zaghaft differenzierter erfahrene und im Medium des Ichs gebrochene Lebenswelten; sie erweitern oftmals nur punktuell geistliche Sprach- und Erzählparadigmen, gemäß den Bedürfnissen sich erst konstituierender literarischer Gemeinschaften und bezogen auf pragmatische Situationen der Heilsvermittlung. Sie finden aber auch zunehmend explizitere und komplexere Formen, die die Existenz anderer literarischer Reihen und Paradigmen bereits denkbar machen; und zeigen - etwa im Falle der Hochzeit oder des Pilatus - die Immanenz religöser Sprache bereits historisch und literarisch durchdrungen, das theologische System durch Interferenzen mit dem literarischen aufgebrochen. Indem Literaturfähigkeit und Literarizität ineinandergreifen, erscheinen auch grundsätzliche Fragen nach autonomer Sinnkonstitution im Medium der Literatur am Horizont. Diese Freiräume sind zwar nicht notwendige Voraussetzungen für den 'epochalen' Umbruch des fiktionalen Romans, aber immerhin Öffnungen auf Radikalisierungsmöglichkeiten hin, die davor warnen können, Innovation nur unter Maßgabe elementarer Umstrukturierungen zu sehen - die 'Blütezeit' ist mindestens ebenso schon 'Erntezeit.' ${ }^{194}$

191 Der Zusammenhang zwischen (unsystematisch-theoretischer) Positionsbestimmung und der Stellung der historia zum Fächerkanon ist differenziert bei Hans-Werner Goetz, "Die 'Geschichte' im Wissenschaftssystem des Mittelalters," Franz-Josef Schmale, Funktionen und Formen mittelalterlicher Geschichtsschreibung (1985), S. 165-213; wegweisend in der Verbindung von theoretischer Besinnung und Interpretation Gert Melville, "System und Diachronie: Untersuchungen zur theoretischen Grundlegung geschichtsschreiberischer Praxis im Mittelalter," Historisches Jabrbuch, 95 (1975), 33-67 und 308-341.

192 S. Southern (Anm. 185), dt. Ausg., S. 206 u.ö.; Morris (Anm. 185), S. 64ff.; Georg Wieland, "Rationalisierung und Verinnerlichung: Aspekte der geistigen Physiognomie des 12. Jahrhunderts," Philosophie im Mittelalter: Entwicklungslinien und Paradigmen, hrsg. Jan P. Beckmann u.a. (1987), S. 61-79, hier S. $73 \mathrm{ff}$.

193 S. Anton Legner, "Illustres manus," Ornamenta ecclesiae: Kunst und Künstler der Romanik, hrsg. ders., Bd. I (1985), 187-230; Peter Cornelius Claussen, "Künstlerinschriften," ebd., 263-276 (jeweils mit Literatur).

194 S. Johnson (Anm. 183). 
Da zudem auch die theoretischen Elemente des höfischen Romans nicht auf das Phänomen Literatur im allgemeinen zielen, sondern gleichermaßen auf das Werk bezogen bleiben, in das sie sich integrieren und mit dem sie interferieren, da auch sie weiterhin auf den Versuch beschränkt bleiben, Verstehensbedingungen und thematische Horizonte auszuloten, können die Ansätze des 12. Jahrhunderts als durchaus eigenständige Versuche gelten - als Ausdruck nicht nur des 'Vortheoretischen,' sondern auch des 'Mittheoretischen' im Sinne einer 'immanenten Poetik' in Werken, "für welche die Sprache zugleich Substanz und Mittel ist" (Valéry). ${ }^{195}$ Ihr Zusammenhalt ist zumindest einer der Emanzipation von Ausdrucksformen. Ihre Konstitution entwirft zumindest Möglichkeiten epochalen Wandels. Dessen Realisation wird nur als Differential verschiedener Positionen zwischen Noch-nicht und Schon-nicht-mehr greifbar.

${ }^{195}$ Zitat bei G. Scholtz, "Poetik (III. Die Begriffsentwicklung bis zur Gegenwart)," Hist. Wörterb. (Anm. 3), 1021-1023, hier 1023. Grundsätzlicher auf Sprachfunktionen und Textstrukturen bezogen Hans Blumenberg, "Sprachsituation und immanente Poetik," in: ders., Wirklichkeiten in denen wir leben, reclam, 7715 (1981), S. 137-156. 